\title{
Ganglioside GM1 contributes to extracellular/intracellular regulation of insulin resistance, impairment of insulin signaling and down-stream eNOS activation, in human aortic endothelial cells after short- or long-term exposure to TNFa
}

\author{
Norihiko Sasaki ${ }^{1}$, Yoko Itakura ${ }^{1}$ and Masashi Toyoda ${ }^{1}$ \\ ${ }^{1}$ Research Team for Geriatric Medicine, Vascular Medicine, Tokyo Metropolitan Institute of Gerontology, Sakaecho 35-2, \\ Itabashi-Ku, Tokyo 173-0015, Japan
}

Correspondence to: Masashi Toyoda, email: mtoyoda@tmig.or.jp

Keywords: TNFa; vascular insulin resistance; GM1; aortic endothelial cell; aging

Received: June 21, 2017 Accepted: October 15, $2017 \quad$ Published: December 15, 2017

Copyright: Sasaki et al. This is an open-access article distributed under the terms of the Creative Commons Attribution License 3.0 (CC BY 3.0), which permits unrestricted use, distribution, and reproduction in any medium, provided the original author and source are credited.

\section{ABSTRACT}

Vascular insulin resistance induced by inflammatory cytokines leads to the initiation and development of vascular diseases. In humans, circulating TNFa levels are increased during aging, suggesting a correlation between vascular insulin resistance and plasma TNFa levels. Currently, the precise molecular mechanisms of vascular insulin resistance mediated by TNFa are not well characterized. We aimed at clarifying whether glycosphingolipids contribute to vascular insulin resistance after inflammatory stimulation. In this study, we examined vascular insulin resistance using human aortic endothelial cells after treatment with different concentrations of TNFa for different time intervals for mimicking in vivo acute or chronic inflammatory situations. We show that ganglioside GM1 levels on cell membranes change depending on time of exposure to TNFa and its concentration and that the GM1 expression is associated with specific extracellular/intracellular regulation of the insulin signaling cascade. Furthermore, we provide evidence that factors such as aging and senescence affect the regulation of insulin resistance. Our data suggest that GM1 is a key player in the induction of vascular insulin resistance after short- or long-term exposure to TNFa and is a good extracellular target for prevention and cure of vascular diseases.

\section{INTRODUCTION}

Vascular endothelial cells (ECs) constitute the endothelium of blood vessels, which forms an interface between blood and vessel walls and plays important roles in vascular homeostasis. Excessive activation or dysfunction of ECs is considered to lead to the development of vascular-related diseases, including restenosis, arteriosclerosis, and cancer [1]. Insulin signaling regulates important functions in ECs and contributes to the maintenance of vascular integrity. For example, nitric oxide (NO) production upon endothelial NO synthase (eNOS) activation (mediated by insulin signaling) maintains endothelial barrier integrity, leading to inhibition of accumulation and retention of atherogenic apolipoprotein B-containing lipoproteins in the subendothelial space. NO production also suppresses the expression of adhesion molecules on ECs, resulting in inhibition of monocyte and monocyte-derived macrophage accumulation and thus attenuating the progression of atherosclerosis, which accompanies EC injury caused from intracellular deposition of lipid droplets [2-8]. Vascular insulin resistance is therefore considered to play an important role in the pathogenesis of vascular and vascular-related diseases, including type 2 diabetes [8-10]. Inflammatory mediators potentially contribute to vascular insulin resistance [11]. It has been reported that circulating serum levels of the pro-inflammatory cytokine tumor necrosis factor-alpha ( $\mathrm{TNF} \alpha)$ are increased in obese and elderly people and that high serum levels of TNF $\alpha$ are associated with a high prevalence of vascular diseases $[12,13]$. In high-fat diet-fed mice, phosphatase and 
tensin homologue upregulated by TNF $\alpha$ induces vascular insulin resistance [14]. Furthermore, production of TNF $\alpha$ by hypertrophic and senescent adipocytes is known to induce insulin resistance in ECs [9, 15]. Therefore, TNF $\alpha$ is a potential contributor to vascular insulin resistance in elderly people and/or people suffering from obesity. The precise molecular mechanisms of vascular insulin resistance induction via TNF $\alpha$ still remain to be elucidated, particularly in humans and at the cell surface level.

Glycosphingolipids are composed of a glycan structure attached to a lipid tail containing the sphingolipid ceramide. Glycosphingolipids expressed on cell membranes have frequently been used as developmental marker molecules and have been suggested to have important biological functions [16-18]. GM1, one of the gangliosides (molecules composed of glycosphingolipids with one or more sialic acids linked), is a well-known key component of lipid rafts. Changes in GM1 levels affect cell surface expression of raft-associated proteins and contribute to reduce membrane fluidity, leading to several cellular dysfunctions, such as impaired signal transduction [19-21]. It has been demonstrated that gangliosides are fine regulators of insulin signaling and that altered compositions of cell surface gangliosides often result in cellular responses associated with physiopathological conditions $[22,23]$. In 3T3-L1 adipocytes, increased levels of monosialodihexosylganglioside (GM3) upon TNF $\alpha$ stimulation were found to contribute to insulin resistance in pathological conditions such as obesity [24]. Furthermore, it was shown that potent inhibitors of glycosphingolipid synthesis improve ganglioside-mediated insulin sensitivity in mice [25, 26]. We previously demonstrated that increased GM1 levels associated with senescence and aging contribute to insulin resistance in ECs [27]. Thus, gangliosides play important roles in the induction of insulin resistance. It is still unknown, however, whether (and what kinds of) gangliosides contribute to insulin resistance in ECs after TNF $\alpha$ stimulation.

We aimed at clarifying the molecular mechanisms of induction of vascular diseases via inflammation in humans, but due to the high complexity of these mechanisms it is currently difficult to recapitulate the in vivo situation. For this purpose, we designed and performed in vitro experiments representing in vivo acute or chronic vascular inflammatory situations. We examined vascular insulin resistance using non-aged, aged or senescent human ECs after treatment with different concentrations of $\mathrm{TNF} \alpha$ for different time intervals. In particular, we focused on gangliosides of ECs and we hypothesized that changes in the levels of cell surface gangliosides upon TNF $\alpha$ exposure contribute to insulin resistance in ECs. In this study, we demonstrate that GM1 is a key player in the regulation of intensity and duration of vascular insulin resistance by using in vitro models that mimic inflammation in aging humans.

\section{RESULTS}

\section{GM1 levels increase in TNF $\alpha$-treated human aortic ECs (HAECs)}

The amount and composition of gangliosides in cell membranes can change depending on cellular conditions, as for example it was shown for senescent HAECs with increased levels of ganglioside GM1 [17, 18, 27]. It is unknown whether and what kinds of gangliosides are affected in ECs after TNF $\alpha$ stimulation. To study changes in cell surface GM1 levels in TNF $\alpha$-stimulated ECs, we performed fluorescence-activated cell sorting (FACS) analysis of HAECs 3 days after incubation with several concentrations of TNF $\alpha(0.1 \mathrm{ng} / \mathrm{ml}-10 \mathrm{ng} / \mathrm{ml})$. We found that expression of GM1 on cell surfaces increased in a concentration-dependent manner (above $1 \mathrm{ng} / \mathrm{ml}$ ) (Figure 1A and 1B) and that the morphology of treated HAECs changed to spindle-shaped fibroblast-like in the presence of high concentrations of TNF $\alpha$ (above $5 \mathrm{ng}$ / $\mathrm{ml}$ ) (Figure 1C). Thus, $1 \mathrm{ng} / \mathrm{ml} \mathrm{TNF} \alpha$ induces changes in cell surface expression of GM1 without concomitant morphological changes. We next examined changes in the expression of the other three main gangliosides (GM3, GM2, GD1a) in $1 \mathrm{ng} / \mathrm{ml} \mathrm{TNF} \alpha$-treated HAECs. FACS analysis revealed that GM3 and GM2 expression was undetectable; whereas GM1 and GD1a were mainly present on HAECs and that their levels changed in $1 \mathrm{ng} /$ $\mathrm{ml}$ TNF $\alpha$-treated HAECs (Figure 1D). As shown in Figure 1E, GM1 levels significantly increased in $1 \mathrm{ng} / \mathrm{ml} \mathrm{TNF} \alpha-$ treated HAECs compared with control cells, whereas GD1a levels decreased. Immunocytochemical staining confirmed these results (Supplementary Figure 1). To elucidate the mechanisms contributing to the observed increase in GM1 levels upon exposure to TNF $\alpha$, we analyzed the expression levels of the glycosyltransferases involved in the ganglioside synthetic pathways (Figure 1F) and of sialidase (NEU3), which modulates ganglioside content by removing sialic acid [28]. Real-time PCR analysis showed that the expression of B4GALNT1, which catalyzes the synthesis of GM2 prior to GM1 synthesis, was significantly increased and that expression of ST8SIA1, which does not contribute to the GM1 synthetic pathway, was decreased in $1 \mathrm{ng} / \mathrm{ml} \mathrm{TNF} \alpha$-treated HAECs compared with control cells (Figure 1G). These changes in glycosyltransferase expression are therefore likely to positively contribute to the GM2 and GM1 synthetic pathway, presumably resulting in the upregulation of GM1 in TNF $\alpha$-treated HAECs.

\section{Increased GM1 levels contribute to insulin signaling reduction in $1 \mathrm{ng} / \mathrm{ml} \mathrm{TNF} \alpha$-treated HAECS}

In our previous report, we demonstrated that GM1 on the cell surface contributes to insulin resistance in 
HAECs [27]. We then hypothesized that increased GM1 levels in TNF $\alpha$-treated HAECs result in impaired insulin signaling. We first examined the expression levels of insulin signaling molecules, such as the insulin receptor (IR) and IR substrate (IRS). IR expression was not altered at the cell surface after exposure to $1 \mathrm{ng} / \mathrm{ml} \mathrm{TNF} \alpha$ for 3 days (Figure 2A and Supplementary Figure 2A). Furthermore, mRNA levels of IRS1, IRS2 and eNOS did not significantly change (Figure $2 \mathrm{~B}$ and Supplementary Figure 3A). Next, we examined insulin signaling in $1 \mathrm{ng} /$ $\mathrm{ml}$ TNF $\alpha$-treated HAECs with increased GM1 (Figure 2C) by monitoring the levels of phosphorylated protein kinase B (AKT) and eNOS, which are molecules involved in the insulin signaling cascade [29]. Western blot analysis showed that insulin-induced phosphorylation of AKT and eNOS was reduced in $1 \mathrm{ng} / \mathrm{ml} \mathrm{TNF} \alpha$-treated HAECs compared to control cells without a concomitant significant reduction in AKT and eNOS levels (Figure $2 \mathrm{D}$ and $2 \mathrm{E})$. In order to clarify the effect of increased GM1 levels, we used $N$-(5'-adamantane-1' -yl-methoxy)pentyl-1-deoxynojirimycin (AMP-dNM). AMP-dNM is a specific inhibitor of glucosylceramide synthase that can be used to study the functional roles of endogenous gangliosides $[25,30]$. In our previous study, we employed this inhibitor to investigate the effect of increased GM1 levels [27]. Treatment with AMP-dNM resulted in a
A

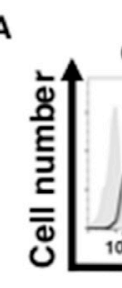

$\mathrm{TNF} \alpha(\mathrm{ng} / \mathrm{ml})$

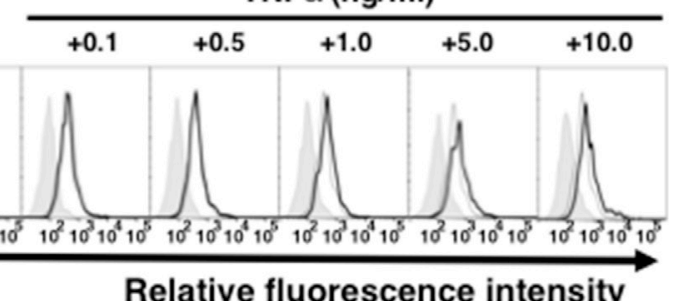

Relative fluorescence intensity

C

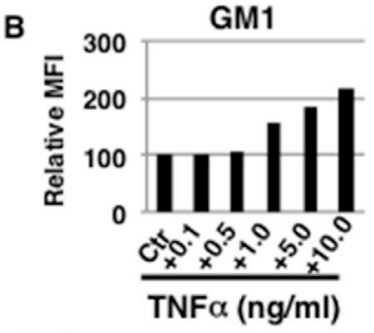

$\mathrm{TNF} \alpha(\mathrm{ng} / \mathrm{ml})$

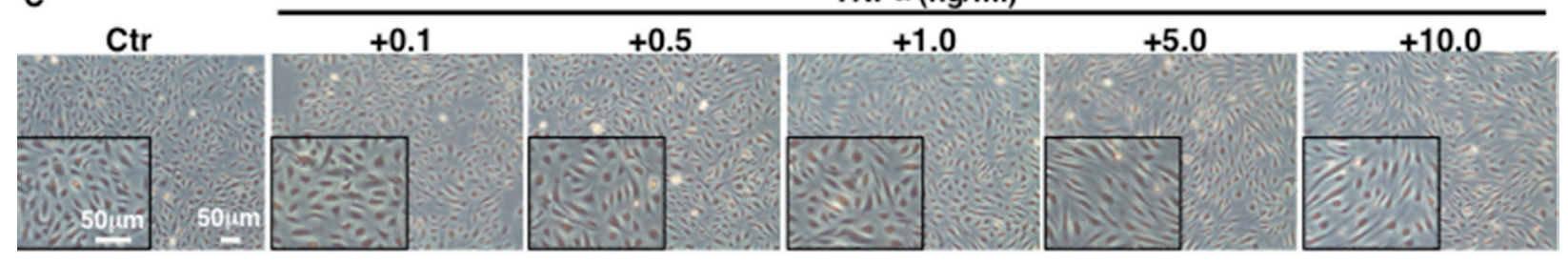

D

D
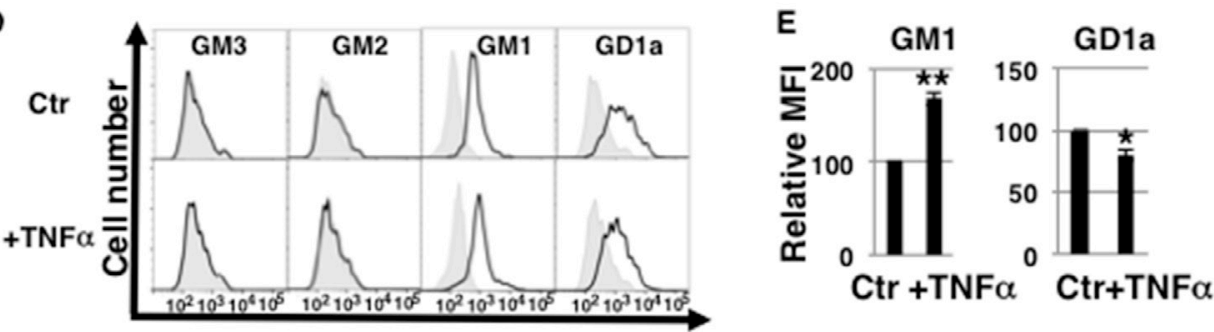

F

Relative fluorescence intensity

$\mathrm{Ctr}+\mathrm{TNF} \alpha \quad \mathrm{Ctr}+\mathrm{TNF} \alpha$

G
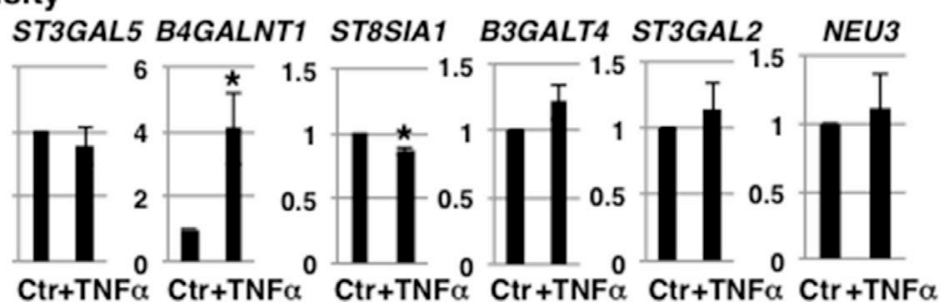

Figure 1: Ganglioside GM1 levels increase in TNF $\boldsymbol{\alpha}$-treated HAECs. (A) Levels of GM1 in TNF $\alpha$-treated HAECs analyzed by flow cytometry. Representative results are shown. GM1 expression in control cells and negative controls is depicted by black dot lines and thin gray lines, respectively. (B) Mean fluorescence intensities (MFIs) of GM1 expression relative to control HAECs. (C) Representative photos of HAECs 3 days after exposure to TNF $\alpha(0.1 \mathrm{ng} / \mathrm{ml}-10 \mathrm{ng} / \mathrm{ml})$. Inset image is at high magnification. (D) Cell surface levels of gangliosides in short-term ( 3 days) $1 \mathrm{ng} / \mathrm{ml} \mathrm{TNF} \alpha$-treated HAECs analyzed by flow cytometry using antibodies against each ganglioside. Representative results are shown. Negative controls are depicted by thin gray lines. (E) MFIs relative to control HAECs. Results are presented as means \pm SD from three independent experiments. (F) Pathways of gangliosides and glycosyltransferases contributing to each synthetic pathway. Gangliosides highlighted in red fonts were examined in this study. (G) Real-time PCR analysis of the glycosyltransferases shown in (F) and NEU3 using cDNA derived from control and short-term (3 days) $1 \mathrm{ng} / \mathrm{ml}$ TNF $\alpha$-treated HAECs. The results are shown after normalization against values obtained for control HAECs (value $=1$ ). Results are presented as means $\pm \mathrm{SD}$ from three independent experiments. ${ }^{*} P<0.05 ;{ }^{* *} P<0.01$. Control (Ctr): untreated cells. 
decrease in GM1 levels of $1 \mathrm{ng} / \mathrm{ml}$ TNF $\alpha$-treated HAECs that was comparable to the one detected in control cells (Figure 2C). Western blot analysis showed that reduction of insulin-induced phosphorylation of AKT and eNOS was not caused by AMP-dNM treatment, indicating that insulin signaling in $\mathrm{TNF} \alpha$-treated HAECs could normally occur upon AMP-dNM treatment (Figure 2D and 2E). In control HAECs, there were no significant differences in insulin signaling before and after AMP-dNM treatment, indicating that AMP-dNM does not affect insulin signaling (data not shown). It has been demonstrated that interaction between GM3/GM1 and IR is required
A

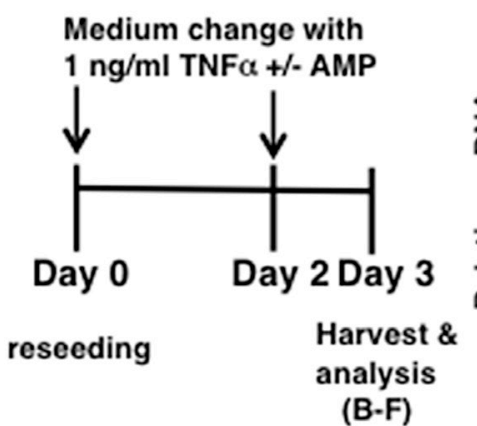

D

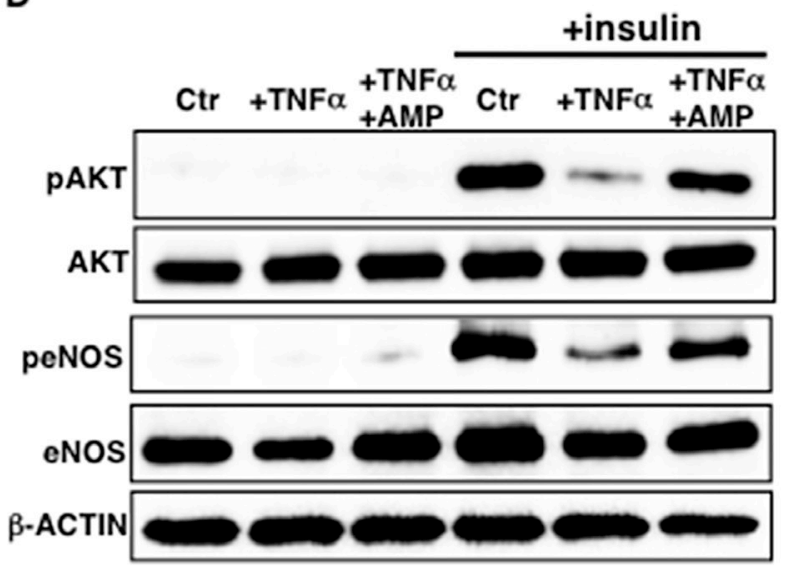

F

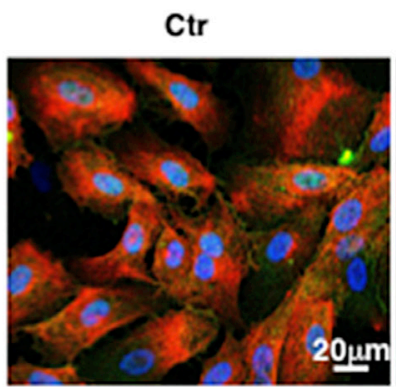

B

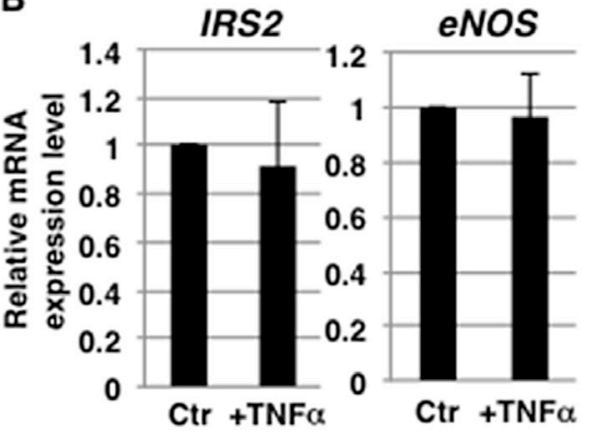

C

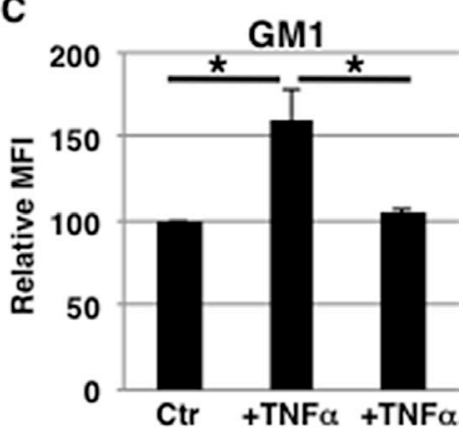

E

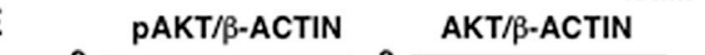

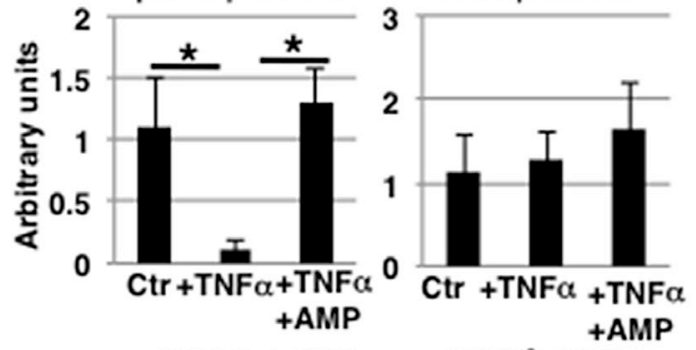

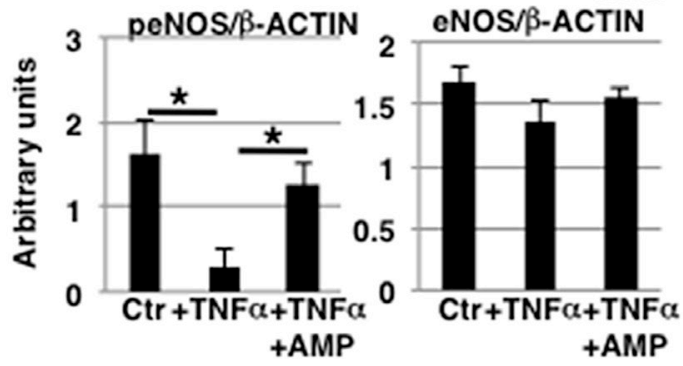

+ TNF $\alpha$

+AMP
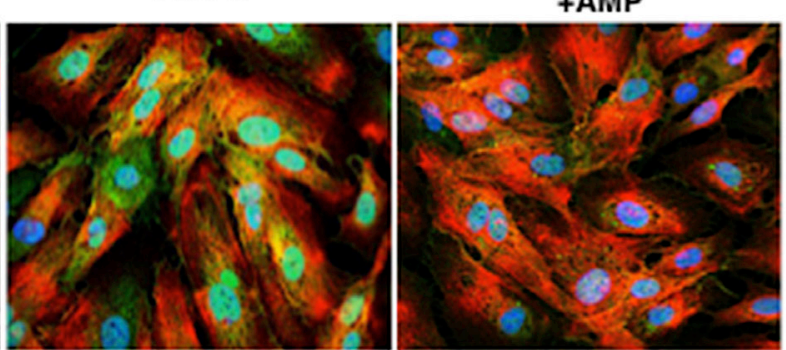

Figure 2: Increased GM1 levels in $1 \mathrm{ng} / \mathrm{ml}$ TNF $\alpha$-treated HAECs reduce insulin signaling. (A) At day 0, cells were reseeded with $1 \mathrm{ng} / \mathrm{ml} \mathrm{TNF} \alpha$ and with or without AMP-dNM in HAEC medium and incubated for 3 days. At day 3, cells were harvested and analyzed (B-F). Control cells were grown in HAEC medium. (B) Real-time PCR analysis of IRS2 and eNOS performed using cDNA derived from control and TNF $\alpha$-treated HAECs. Results shown were normalized against values obtained for control HAECs $($ value $=1)$. $($ C) Cell surface levels of GM1 in TNF $\alpha$-treated HAECs with or without AMP-dNM treatment analyzed by flow cytometry. MFIs of three independent experiments relative to control HAECs are shown. (D) Western blot analysis of insulin signaling performed in TNF $\alpha$-treated HAECs with or without AMP-dNM treatment. (E) Histograms show mean densitometric readings \pm SD of phosphorylated or non-phosphorylated proteins in insulin-stimulated cells normalized to loading control ( $\beta$-ACTIN). All values were obtained from three independent experiments. (F) Immunocytochemical staining performed in TNF $\alpha$-treated HAECs with or without AMP-dNM treatment. Representative images are shown (GM1, green; IR $\alpha$, red; DAPI, blue; GM1 and IR $\alpha$ co-localization, yellow). ${ }^{*} P<0.05$. Control (Ctr): untreated cells. 
for insulin resistance [27, 31]. We therefore examined whether GM1 and IR interacted in $1 \mathrm{ng} / \mathrm{ml} \mathrm{TNF} \alpha$-treated HAECs. Immunocytochemical staining showed that GM1 co-localized with cell surface IR on $1 \mathrm{ng} / \mathrm{ml} \mathrm{TNF} \alpha$-treated HAECs. Co-localization could not be observed upon AMP-dNM treatment (Figure 2F). These results indicate that increased levels of GM1 on the surface of $1 \mathrm{ng} / \mathrm{ml}$ $\mathrm{TNF} \alpha$-treated HAECs contribute to insulin resistance.

\section{Reduction of eNOS levels in long-term $1 \mathrm{ng} / \mathrm{ml}$ TNF $\alpha$-treated HAECs is inhibited upon AMP- dNM treatment}

Chronic vascular inflammation leads to pathogenesis of vascular diseases, although the precise molecular mechanisms of vascular insulin resistance mediated by chronic inflammation are not well characterized [32, 33]. As in vitro model of chronic inflammation, we examined the long-term (7 days) effect of $1 \mathrm{ng} / \mathrm{ml} \mathrm{TNF} \alpha$ exposure on HAECs (Figure 3A). Cell surface IR expression was not significantly increased (Supplementary Figure 2B). Long-term (7 days) exposure significantly reduced mRNA levels of eNOS, but not of IRS2 (Figure 3B). Notably, AMP-dNM treatment inhibited downregulation of mRNA (Figure 3B) and protein levels of eNOS (Figure 3D and $3 \mathrm{E}$ ) accompanying a reduction in GM1 levels (Figure 3C), suggesting that increased GM1 upon $\mathrm{TNF} \alpha$ exposure may affect the expression of eNOS. Next, we examined insulin signaling in long-term $1 \mathrm{ng} / \mathrm{ml} \mathrm{TNF} \alpha$-treated HAECs. Western blot analysis showed that insulin-induced phosphorylation of AKT and eNOS was reduced in longterm $1 \mathrm{ng} / \mathrm{ml} \mathrm{TNF} \alpha$-treated HAECs compared to control cells, indicating that insulin signaling was impaired after long-term $1 \mathrm{ng} / \mathrm{ml} \mathrm{TNF} \alpha$ treatment (Figure 3D and 3E). In AMP-dNM treated cells, insulin-induced phosphorylation of AKT and eNOS was not reduced, indicating that the impairment of insulin signaling and down-stream eNOS activation (peNOS/ $\beta$-ACTIN) in long-term $1 \mathrm{ng} / \mathrm{ml}$ TNF $\alpha$-treated HAECs was not induced by AMP-dNM treatment (Figure 3D and 3E). Immunocytochemical staining showed that GM1 co-localized with cell surface IR in long-term $1 \mathrm{ng} / \mathrm{ml} \mathrm{TNF} \alpha$-treated HAECs but not upon AMP-dNM treatment (Figure 3F), indicating that increased GM1 levels upon TNF $\alpha$ exposure contribute to impair insulin signaling. Thus, we demonstrated that long-term ( 7 days) exposure to $1 \mathrm{ng} / \mathrm{ml} \mathrm{TNF} \alpha$ induces GM1-dependent impairment of insulin signaling and down-stream eNOS activation together with a decrease in eNOS levels.

\section{GM1 expression is reversible in $1 \mathrm{ng} / \mathrm{ml} \mathrm{TNF} \alpha-$ treated HAECs}

Prolonged inflammatory response has a detrimental effect on the function of vasculature, therefore appropriate control of the duration of an inflammatory response is important [34]. We speculated that a prolonged duration of vascular insulin resistance via increased GM1 expression may have a detrimental effect. In order to investigate the stability of TNF $\alpha$-mediated GM1 induction, we treated HAECs with $1 \mathrm{ng} / \mathrm{ml} \mathrm{TNF} \alpha$ for 3 days and then removed TNF $\alpha$ (Figure 4A). The expression levels of GM1 and the enzyme that catalyzes its synthesis, B4GALNT1, were comparable to those of control cells upon removal of TNF $\alpha$ (Figure 4B and 4C) and insulin signaling was restored (Figure 4D). Furthermore, to determine the stability of GM1 and investigate the reduction of eNOS expression in long-term $1 \mathrm{ng} / \mathrm{ml} \mathrm{TNF} \alpha$-treated HAECs, we examined their expression levels after removal of $\mathrm{TNF} \alpha$ (Figure 4E). We found that the expression levels of GM1 and also B4GALNT1 were comparable to those of control cells upon removal of TNF $\alpha$ (Figure $4 \mathrm{~F}$ and $4 \mathrm{G}$ ) and that insulin signaling and down-stream eNOS activation were restored together with eNOS levels (Figure 4H and 4I). Thus, we demonstrated that GM1 expression and insulin signaling are restored in $1 \mathrm{ng} / \mathrm{ml}$ TNF $\alpha$-treated HAECs after removal of TNF $\alpha$.

\section{eNOS activation is attenuated independently of GM1 in $10 \mathrm{ng} / \mathrm{ml}$ TNF $\alpha$-treated HAECs}

The intensity of inflammatory responses is an important factor in the pathogenesis of vascular diseases [33]. As described above, the increase in GM1 levels observed in TNF $\alpha$-treated HAECs was dependent on TNF $\alpha$ concentration (above $1 \mathrm{ng} / \mathrm{ml}$ ) (Figure 1A and 1B). We therefore examined the effect of highly concentrated TNF $\alpha$ exposure on HAECs (Figure 5A). Cell surface IR expression did not change upon short-term (3 days) exposure to $10 \mathrm{ng} / \mathrm{ml} \mathrm{TNF} \alpha$ (Supplementary Figure 2C). In contrast, compared with $1 \mathrm{ng} / \mathrm{ml} \mathrm{TNF} \alpha$ treatment, 10 $\mathrm{ng} / \mathrm{ml} \mathrm{TNF} \alpha$ exposure for 3 days reduced mRNA levels of IRS2 and eNOS, but not of IRS1 (Figure 5B and Supplementary Figure 3B). Next, we examined insulin signaling in $10 \mathrm{ng} / \mathrm{ml} \mathrm{TNF} \alpha$-treated HAECs as we did for $1 \mathrm{ng} / \mathrm{ml} \mathrm{TNF} \alpha$-treated HAECs. Western blot analysis showed that insulin-induced phosphorylation of AKT and eNOS was reduced in $10 \mathrm{ng} / \mathrm{ml} \mathrm{TNF} \alpha$-treated HAECs with a concomitant increase in GM1 levels compared to control cells, indicating a reduction in insulin signaling and down-stream eNOS activation (Figure 5C-5E). Treatment with AMP-dNM downregulated GM1 in 10 $\mathrm{ng} / \mathrm{ml} \mathrm{TNF} \alpha$-treated HAECs to levels comparable to the ones of control cells (Figure 5C). In addition, Western blot analysis showed that the impairment of insulin signaling and down-stream eNOS activation was not restored upon AMP-dNM treatment (Figure 5D and 5E), although immunocytochemical staining showed that GM1 did not co-localize with cell surface IR in $10 \mathrm{ng} / \mathrm{ml} \mathrm{TNF} \alpha$-treated HAECs upon AMP-dNM treatment (Figure 5F). In $10 \mathrm{ng} /$ $\mathrm{ml}$ TNF $\alpha$-treated HAECs, downregulation of mRNA levels of IRS2 and of both mRNA and protein levels of eNOS 
was not inhibited upon AMP-dNM treatment, suggesting that these downregulation mechanisms observed after highly concentrated TNF $\alpha$ exposure are independent of GM1 (Figure 5B, 5D and 5E). Upon short-term (3 days) exposure to $10 \mathrm{ng} / \mathrm{ml} \mathrm{TNF} \alpha$, HAECs acquired spindle-shaped fibroblast-like morphologies (Figure 1C). Real-time PCR, immunocytochemical staining and FACS analysis revealed that endothelial-mesenchymal transition (EndMT)-like differentiation was induced in $10 \mathrm{ng} / \mathrm{ml} \mathrm{TNF} \alpha$-treated HAECs (Supplementary Figure 4). Taken together, these results indicate that insulin signaling and down-stream eNOS activation are attenuated independently of GM1 in $10 \mathrm{ng} / \mathrm{ml} \mathrm{TNF} \alpha$-treated HAECs accompanying EndMT-like differentiation.

\section{Induction of GM1 expression is stable in $10 \mathrm{ng} /$ mI TNF $\alpha$-treated HAECs}

After short-term (3 days) $10 \mathrm{ng} / \mathrm{ml}$ TNF $\alpha$ treatment, the endothelial marker CD31 was fully expressed in HAECs (Supplementary Figure 4C). It could therefore be hypothesized that EndMT-like differentiation was partial and could be reversed. We tested this in shortterm $10 \mathrm{ng} / \mathrm{ml}$ TNF $\alpha$-treated HAECs (Figure 6A). Four days after withdrawal of TNF $\alpha$, mRNA levels of IRS2 and eNOS in short-term $10 \mathrm{ng} / \mathrm{ml}$ TNF $\alpha$-treated HAECs were comparable to those of control cells (Figure 6B). This restoration accompanied an almost complete reinstatement of the expression levels of EndMT markers
A

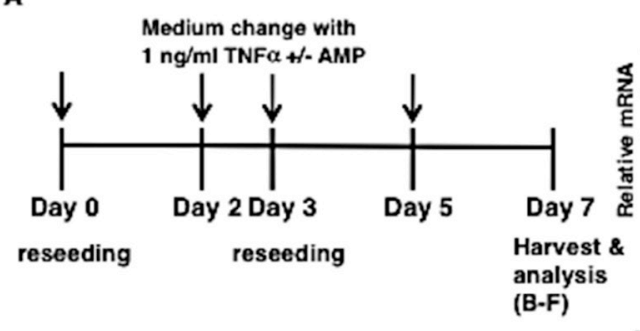

B
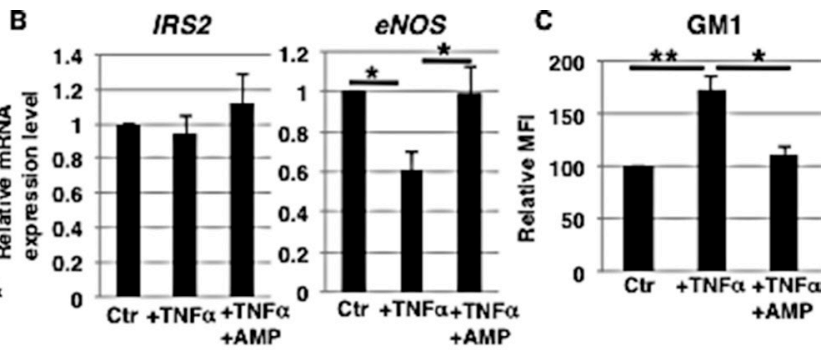

D

E
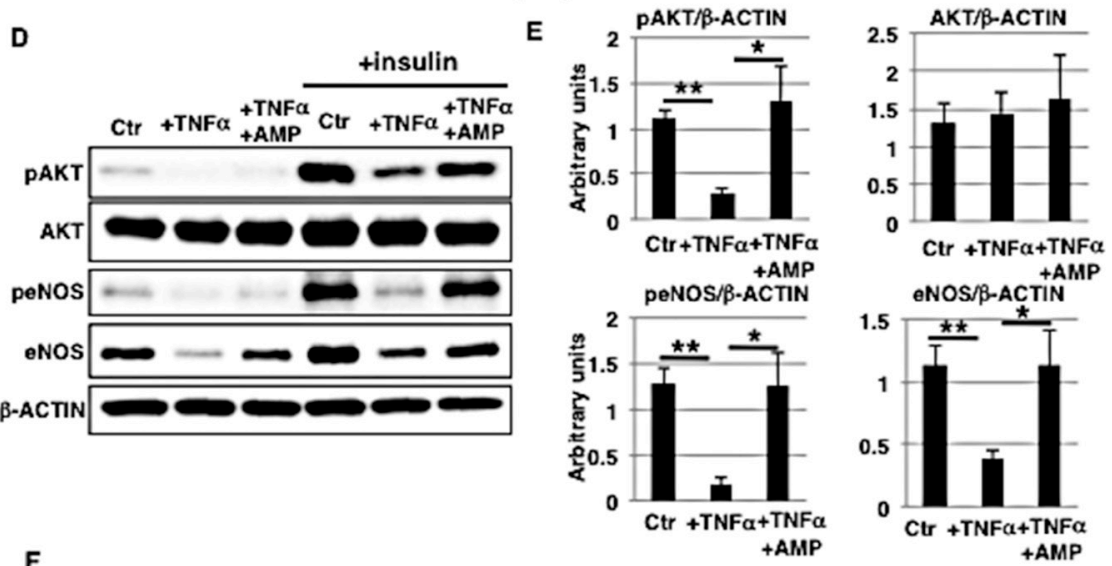

$\mathbf{F}$
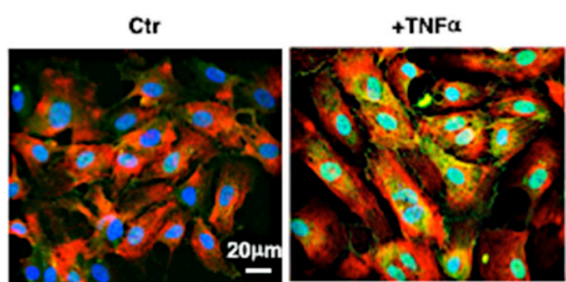

+ TNF $\alpha$ $+A M P$

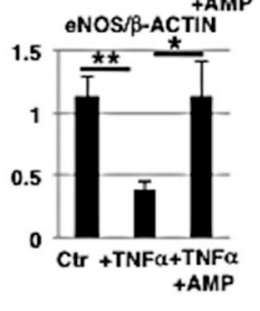

Figure 3: Reduction of eNOS levels in long-term $1 \mathrm{ng} / \mathrm{ml}$ TNF $\alpha$-treated HAECs is inhibited by AMP-dNM treatment. (A) At day 0, cells were reseeded with $1 \mathrm{ng} / \mathrm{ml} \mathrm{TNF} \alpha$ and with or without AMP-dNM in HAEC medium and incubated for 3 days. At day 3 , cells were reseeded with $1 \mathrm{ng} / \mathrm{ml} \mathrm{TNF} \alpha$ and with or without AMP-dNM in HAEC medium and subsequently incubated for 4 days. At day 7, cells were harvested and analyzed (B-F). Control cells were grown in HAEC medium. (B) Real-time PCR analysis of IRS2 and eNOS performed using cDNA derived from control and TNF $\alpha$-treated HAECs with or without AMP-dNM treatment. Results shown were normalized against values obtained for control HAECs (value =1). (C) Cell surface levels of GM1 in TNF $\alpha$-treated HAECs with or without AMP-dNM treatment analyzed by flow cytometry. MFIs relative to control HAECs of three independent experiments are shown. (D) Western blot analysis of insulin signaling performed in TNF $\alpha$-treated HAECs with or without AMP-dNM treatment. (E) Histograms show mean densitometric readings $\pm \mathrm{SD}$ of phosphorylated or non-phosphorylated proteins in insulin-stimulated cells normalized to loading controls ( $\beta$-ACTIN). All values were obtained from three independent experiments. (F) Immunocytochemical staining performed in TNF $\alpha$ treated HAECs with or without AMP-dNM treatment. Representative images are shown (GM1, green; IR $\alpha$, red; DAPI, blue; GM1 and IR $\alpha$ co-localization, yellow). ${ }^{*} P<0.05 ;{ }^{* *} P<0.01$. Control (Ctr): untreated cells. 


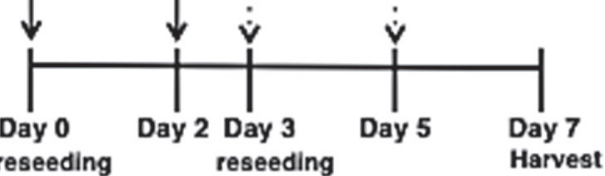

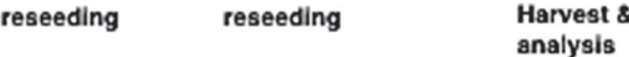

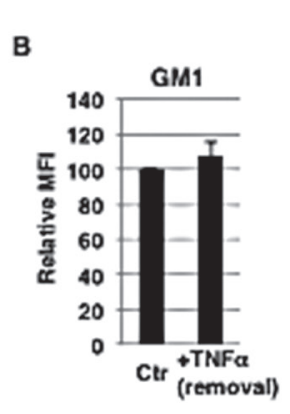

C

(B-D)
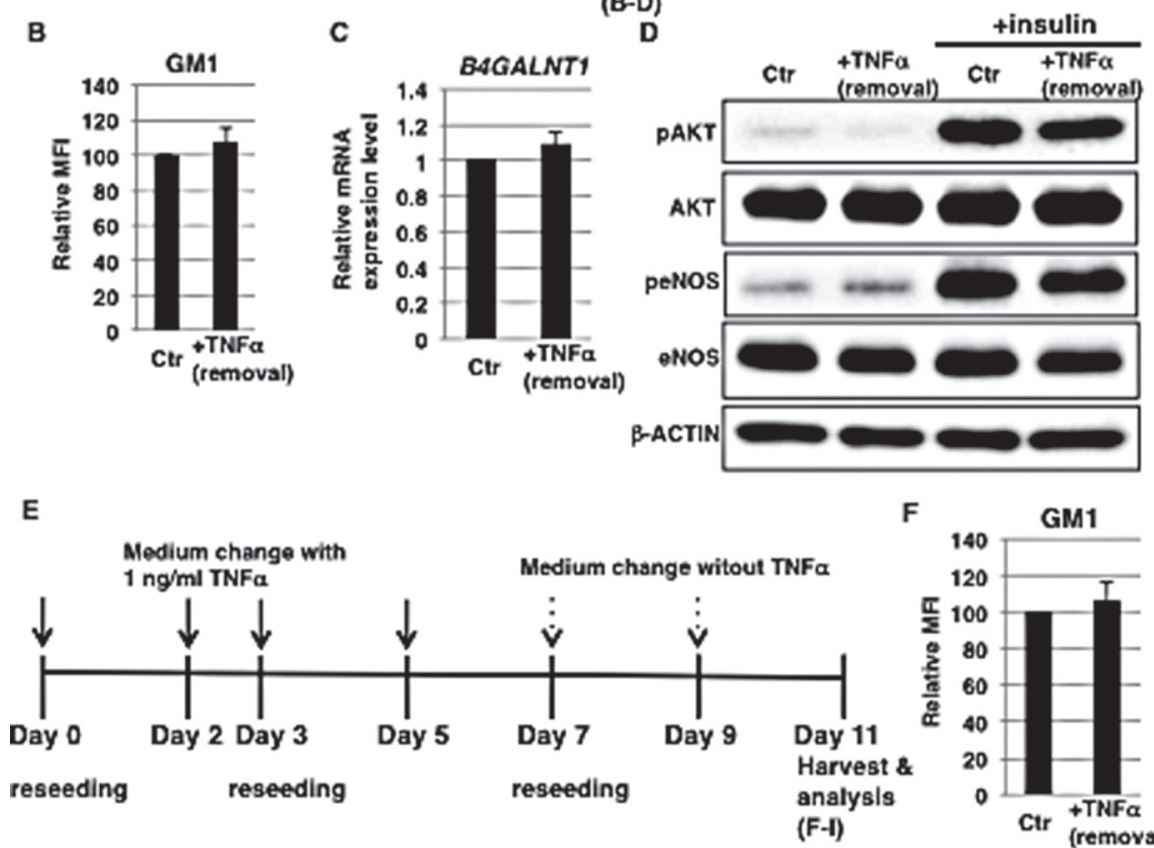

E
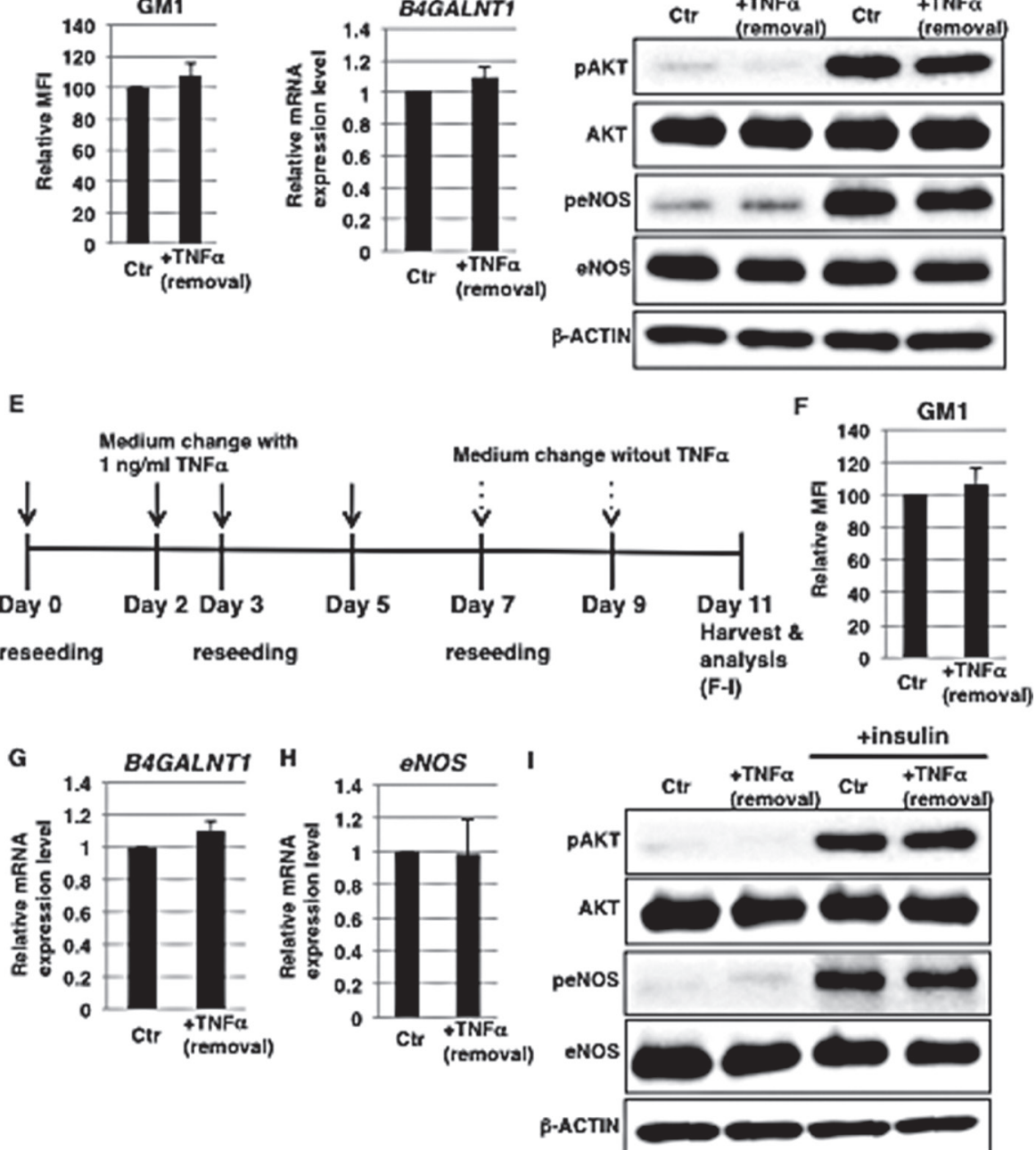

Figure 4: Induction of GM1 expression is reversible in $1 \mathrm{ng} / \mathrm{ml}$ TNF $\alpha$-treated HAECs. (A) At day 0, cells were reseeded with $1 \mathrm{ng} / \mathrm{ml}$ TNF $\alpha$ in HAEC medium and incubated for 3 days. At day 3, cells were reseeded without TNF $\alpha$. Control cells were grown in HAEC medium. (B) Cell surface levels of GM1 in short-term (3 days) $1 \mathrm{ng} / \mathrm{ml}$ TNF $\alpha$-treated HAECs 4 days after removal of TNF $\alpha$ analyzed by flow cytometry. MFIs relative to control HAECs of three independent experiments are shown. (C) Real-time PCR analysis of B4GALNT1 performed using cDNA derived from control and short-term (3 days) $1 \mathrm{ng} / \mathrm{ml} \mathrm{TNF \alpha -treated} \mathrm{HAECs} 4$ days after removal of $\mathrm{TNF} \alpha$. Results shown were normalized against the values obtained for control HAECs (value $=1$ ). Results are presented as means $\pm \mathrm{SD}$ from three independent experiments. (D) Western blot analysis of insulin signaling performed for short-term (3 days) $1 \mathrm{ng} / \mathrm{ml} \mathrm{TNF} \alpha$-treated HAECs 4 days after removal of TNF $\alpha$. (E) At day 0 , cells were reseeded with $1 \mathrm{ng} / \mathrm{ml}$ TNF $\alpha$ in HAEC medium and incubated for 3 days. At day 3, cells were reseeded with $1 \mathrm{ng} / \mathrm{ml} \mathrm{TNF} \alpha$ in HAEC medium and further incubated for 4 days. At day 7 , cells were reseeded without TNFa. Control cells were grown in HAEC medium. (F) Cell surface levels of GM1 in long-term (7 days) $1 \mathrm{ng} / \mathrm{ml}$ TNF $\alpha$-treated HAECs 4 days after removal of TNF $\alpha$ analyzed by flow cytometry. MFIs relative to control HAECs of three independent experiments are shown. (G) Real-time PCR analysis of B4GALNT1 performed using cDNA derived from control and long-term (7 days) $1 \mathrm{ng} / \mathrm{ml} \mathrm{TNF} \alpha$-treated HAECs 4 days after removal of TNF $\alpha$. Results shown were normalized against values obtained for control HAECs $($ value $=1$ ). Results are presented as means \pm SD from three independent experiments. (H) Real-time PCR analysis of eNOS performed using cDNA derived from control and long-term (7 days) $1 \mathrm{ng} / \mathrm{ml} \mathrm{TNF} \alpha$-treated HAECs 4 days after removal of TNF $\alpha$. Results shown were normalized against the values obtained for control HAECs (value $=1$ ). Results are presented as means \pm SD from three independent experiments. (I) Western blot analysis of insulin signaling performed for long-term ( 7 days) $1 \mathrm{ng} / \mathrm{ml} \mathrm{TNF} \alpha$-treated HAECs 4 days after removal of TNF $\alpha$. Control (Ctr): untreated cells. 
(Supplementary Figure 5). These results suggest that downregulation of mRNA levels of IRS2 and eNOS in $10 \mathrm{ng} / \mathrm{ml} \mathrm{TNF} \alpha$-treated HAECs is dependent on EndMTlike differentiation. In summary, we showed that EndMTlike differentiation in short-term $10 \mathrm{ng} / \mathrm{ml} \mathrm{TNF} \alpha$-treated
HAECs was reversible, whereas GM1 and B4GALNT1 expression remained at high levels (Figure 6C and 6D), unlike for $1 \mathrm{ng} / \mathrm{ml} \mathrm{TNF} \alpha$-treated HAECs.

It has been recently reported that long-term ( 6 days) exposure to highly concentrated $\mathrm{TNF} \alpha$ induces premature
A

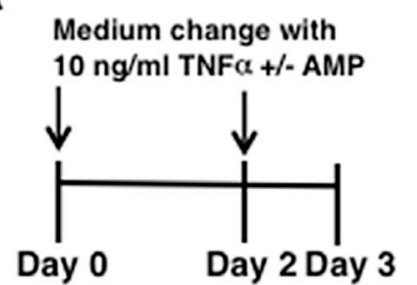

reseeding
B

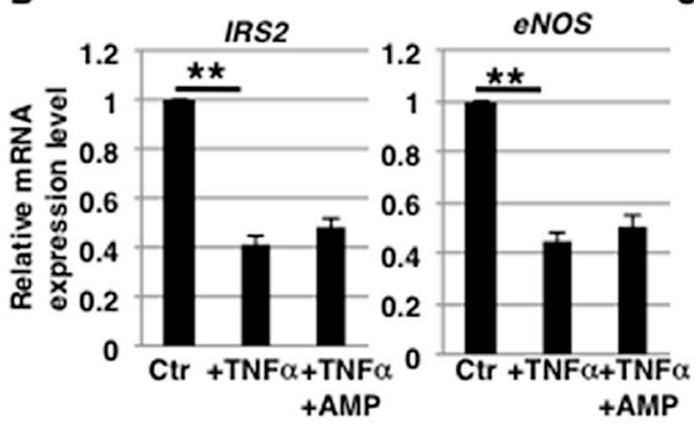

C

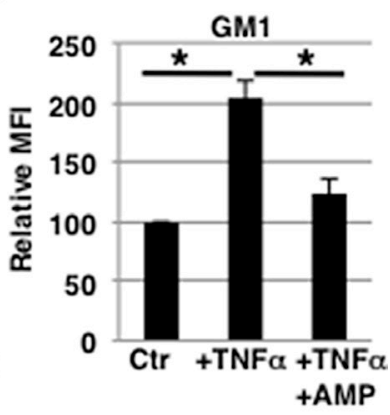

D

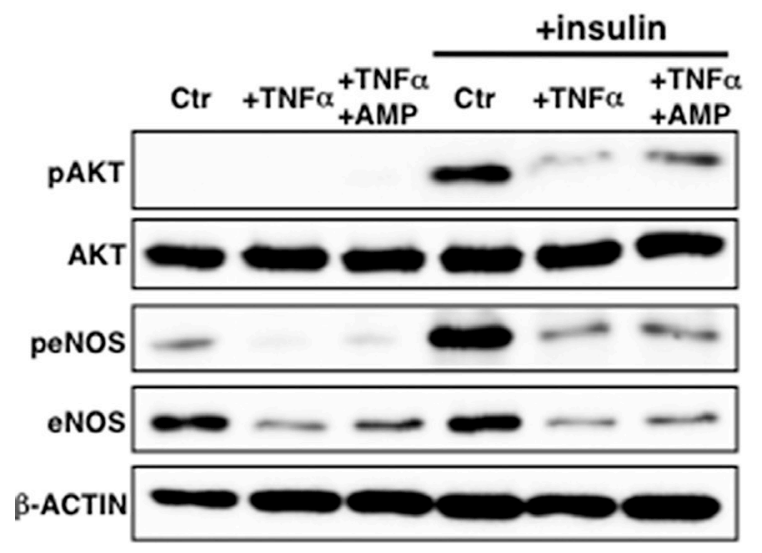

F
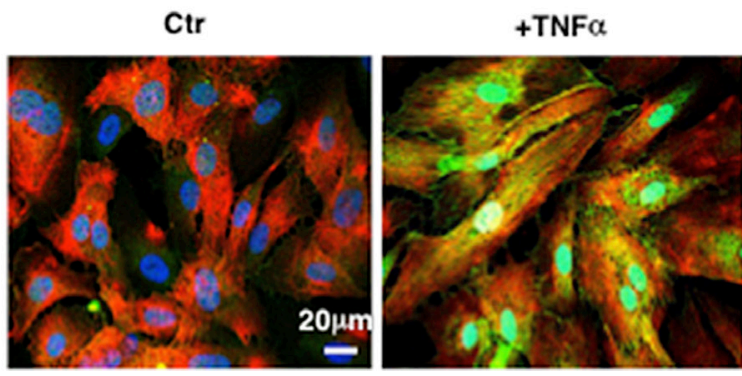

E
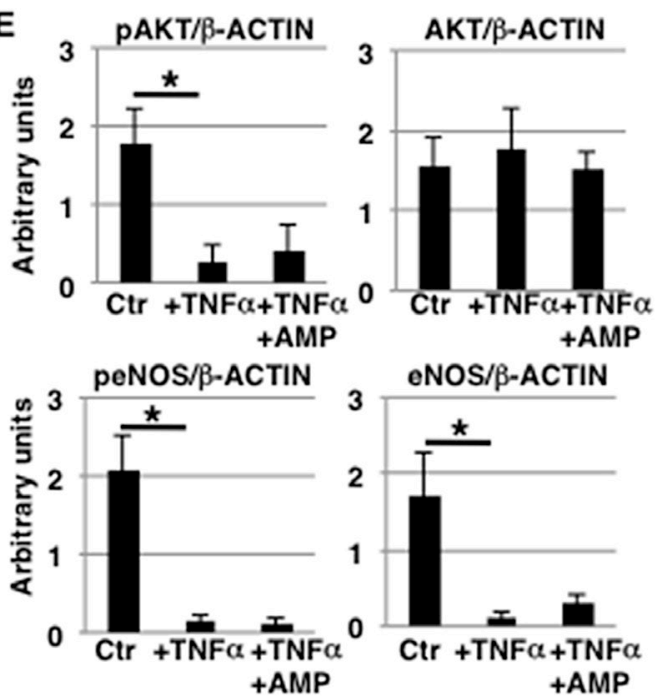
eNOS/B-ACTIN

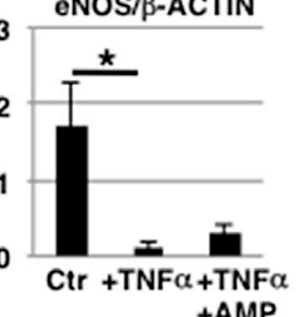

+ TNF $\alpha$ +AMP

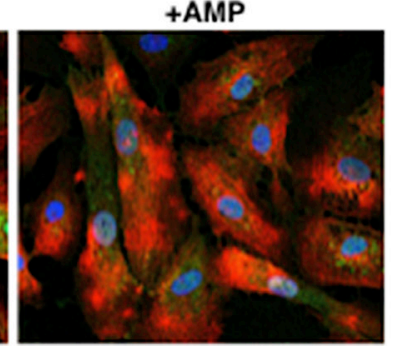

Figure 5: eNOS activation is attenuated independently of GM1 in 10 ng/ml TNF $\alpha$-treated HAECs. (A) At day 0, cells were reseeded with $10 \mathrm{ng} / \mathrm{ml} \mathrm{TNF} \alpha$ and with or without AMP-dNM in HAEC medium and incubated for 3 days. At day 3, cells were harvested and analyzed (B-F). Control cells were grown in HAEC medium. (B) Real-time PCR analysis of IRS 2 and eNOS performed using cDNA derived from control and TNF $\alpha$-treated HAECs with or without AMP-dNM treatment. The results shown were normalized against the values obtained for control HAECs (value = 1). (C) Cell surface levels of GM1 in TNF $\alpha$-treated HAECs with and without AMPdNM treatment analyzed by flow cytometry. MFIs relative to control HAECs of three independent experiments are shown. (D) Western blot analysis of insulin signaling performed for TNF $\alpha$-treated HAECs with or without AMP-dNM treatment. (E) Histograms show mean densitometric readings \pm SD of phosphorylated or non-phosphorylated proteins in insulin-stimulated cells normalized to loading controls $(\beta$-ACTIN). All values were obtained from three independent experiments. (F) Immunocytochemical staining performed in TNF $\alpha$-treated HAECs with or without AMP-dNM treatment. Representative images are shown (GM1, green; IR $\alpha$, red; DAPI, blue; GM1 and IR $\alpha$ colocalization, yellow). ${ }^{*} P<0.05 ;{ }^{* *} P<0.01$. Control (Ctr): untreated cells. 
senescence in human umbilical vein ECs via reactive oxygen species (ROS) production [35]. In our previous report, we showed that premature senescence induced by ROS increases GM1 levels with a concomitant increased expression of B4GALNT1 in HAECs [27]. We therefore examined the possible induction of premature senescence in HAECs reversed from EndMT-like differentiation. In our senescence assay (Supplementary Figure 6), the senescence marker $p 16^{I N K 4 a}$ and senescence-associated $\beta$-galactosidase (SA- $\beta$-Gal) levels were moderately but consistently increased in reversed HAECs compared to control cells, suggesting that cellular senescence was partially induced in reversed HAECs. Induction of GM1 upon $10 \mathrm{ng} / \mathrm{ml} \mathrm{TNF} \alpha$ exposure for 3 days therefore appeared to be highly stable, presumably depending on partial induction of premature senescence, even in the absence of initiating stimuli.

It is likely that GM1-dependent insulin resistance is still induced in reversed HAECs with increased GM1 levels. We next examined insulin signaling in reversed HAECs. Western blot analysis showed that insulininduced phosphorylation of AKT and eNOS was reduced in reversed HAECs compared to control cells, without a concomitant reduction of AKT, eNOS and cell surface IR expression (Figure 6E, 6F and Supplementary Figure 2D). Treatment with AMP-dNM reduced GM1 levels in reversed HAECs to the same extent as in control cells (Figure 6C). We did not detect a reduction of insulin-induced phosphorylation of AKT and eNOS in AMP-dNM treated cells, indicating that the impairment of insulin signaling was not induced by AMP-dNM treatment (Figure 6E and 6F). Immunocytochemical staining showed that GM1 co-localized with cell surface IR in reversed HAECs but not upon AMP-dNM treatment (Figure 6G), indicating that the residual GM1 in reversed HAECs contributes to impair insulin signaling. These results clearly indicate that the residual GM1 in reversed HAECs is responsible for insulin resistance. Thus, we demonstrated that short-term exposure to $10 \mathrm{ng} / \mathrm{ml} \mathrm{TNF} \alpha$ induces reversible downregulation of IRS2 and eNOS due to EndMT-like differentiation and it is also likely to induce irreversible GM1 expression, probably resulting in chronic insulin resistance.

\section{Aging and senescence affect eNOS levels due to increased GM1 in short-term $1 \mathrm{ng} / \mathrm{ml}$ TNF $\alpha$ - treated HAECs}

In humans, aging and senescence affect cellular responses, leading to pathological disorders [36]. As shown in Figure 3B-3E, increased levels of GM1 in cell membranes affect the expression of eNOS upon TNF $\alpha$ exposure. We showed in our previous report that GM1 levels are increased in aged and senescent HAECs [27]. In order to clarify the effect of aging and senescence on the response of ECs to TNF $\alpha$ in vivo, we examined whether short-term ( 3 days) exposure to $1 \mathrm{ng} / \mathrm{ml} \mathrm{TNF} \alpha$ reduced eNOS levels in aged/senescent HAECs with increased GM1 levels (Figure 7A). We found that even short-term exposure to $1 \mathrm{ng} / \mathrm{ml} \mathrm{TNF} \alpha$ reduced mRNA and protein levels of eNOS in senescent as well as aged HAECs (Figure 7B-7E). This reduction was not induced by AMP-dNM treatment (Figure 7B-7E), which downregulates GM1 expression in aged/senescent HAECs (Supplementary Figure 7A-7C), suggesting that increased GM1 levels in aged/senescent HAECs affect the expression of eNOS after short-term (3 days) exposure to $1 \mathrm{ng} / \mathrm{ml} \mathrm{TNF} \alpha$. Western blot analysis showed that insulin signaling was reduced both in control and TNF $\alpha$-treated aged HAECs and this reduction was not restored upon AMP-dNM treatment (Supplementary Figure 7D). As suggested in our previous report, a partial reduction of GM1 levels in aged HAECs upon AMP-dNM treatment is likely to be one of the reasons why restoration of insulin signaling in aged HAECs could not be observed upon AMP-dNM treatment [27]. Furthermore, to confirm that increased GM1 levels contribute to downregulate eNOS, we investigated eNOS levels in GM1-overexpressing HAECs, which are produced from non-aged HAECs incubated with exogenous GM1 (Figure 7F). In GM1overexpressing HAECs (Supplementary Figure 7E), short-term (3 days) exposure to $1 \mathrm{ng} / \mathrm{ml} \mathrm{TNF} \alpha$ resulted in reduced eNOS levels (Figure $7 \mathrm{G}$ and $7 \mathrm{H}$ ), clearly indicating that increased GM1 levels are associated with lower eNOS levels. Thus, we demonstrated that even short-term exposure to $1 \mathrm{ng} / \mathrm{ml} \mathrm{TNF} \alpha$ induces downregulation of eNOS levels in aged/senescent HAECs due to increased GM1 levels, suggesting that even low concentrations of circulating $\mathrm{TNF} \alpha$ represent a risk factor for vascular insulin resistance caused by reduced eNOS levels in elderly people.

\section{DISCUSSION}

Inflammation has a detrimental effect on the function of vasculature when the mechanisms that regulate the intensity and duration of an acute inflammatory response are compromised. For example, an excessive inflammatory response during sepsis results in organ failure and death due to profound and systemic increases in endothelial cell permeability, while chronic vascular inflammation leads to pathogenesis of type 2 diabetes and drives progression of atherosclerosis [32, 33, 37]. Here, we show the contribution of GM1 to vascular insulin resistance as a vascular inflammatory response to $\mathrm{TNF} \alpha$ stimulation. Our results suggest that GM1 is a key player in the regulation of the intensity and duration of insulin signaling. GM1 contributes to signal regulation at the cell surface or to the regulation of eNOS expression during $\mathrm{TNF} \alpha$ response. It is likely that chronic vascular insulin resistance leading to initiation and progression of vascular diseases is dependent on extracellular GM1 expression 
and therefore GM1 is a good candidate extracellular target for prevention and cure of vascular diseases.

As shown in Figure 1F, GM1 is synthesized by glycosyltransferases and sialidase (NEU3). Altered expression of these enzymes leads to an increased production of GM1. In fact, overexpression of B4GALNT1, $B 3 G A L T 4$ or NEU3 in mammalian cells was reported to induce an increase in the levels of GM1 $[20,28]$. In this study, we found that expression of B4GALNT1, which catalyzes the synthesis of GM2 (a GM1 precursor), was upregulated in TNF $\alpha$-treated HAECs. Furthermore, we observed a reduced expression of ST8SIA1, which is not part of the GM2 and GM1 synthetic pathway, in TNF $\alpha$ treated HAECs. It can be therefore suggested that the GM2 and GM1 synthetic pathway is predominant in TNF $\alpha$ treated HAECs. In the GM1 synthetic pathway, expression of B3GALT4, which catalyzes the synthesis of GM1, was not significantly altered compared with B4GALNT1. We speculate that expression levels of B3GALT4 may be adequate for the conversion of GM2 into GM1 in TNF $\alpha$-treated HAECs. We observed a decrease in the levels of GD1a, but not of ST3GAL2 and NEU3 (which
A
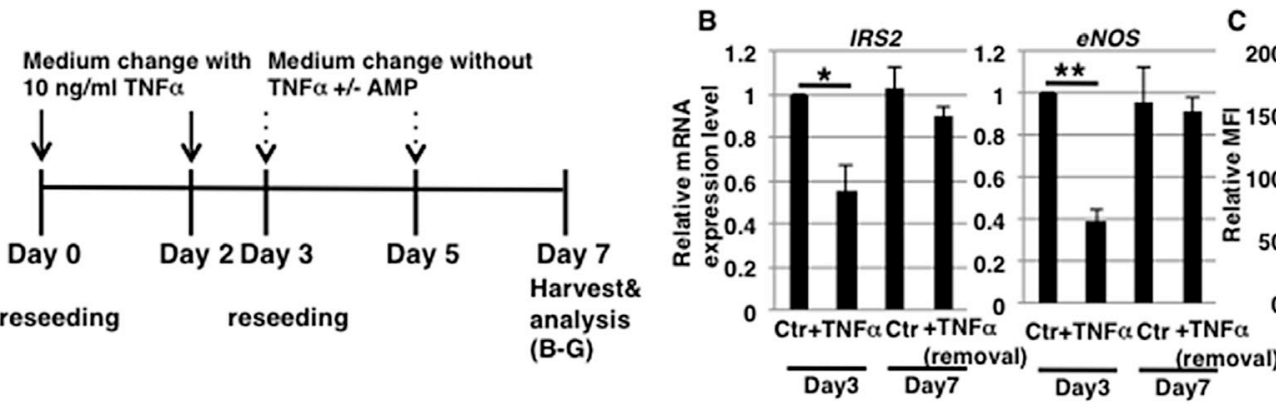

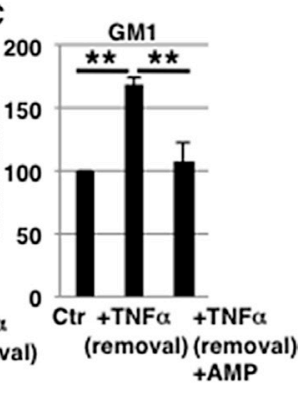

$\mathbf{F}$
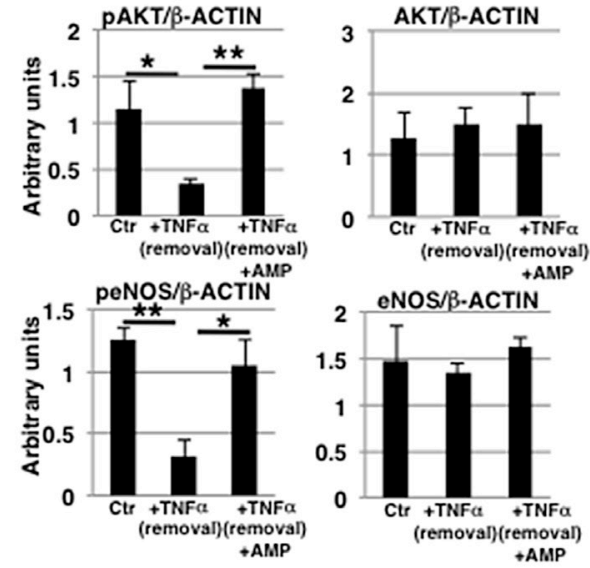

+ AMP

G

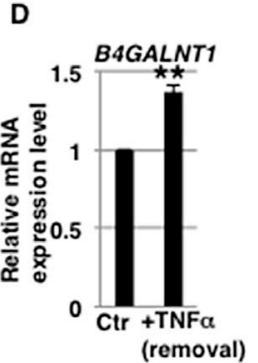

E

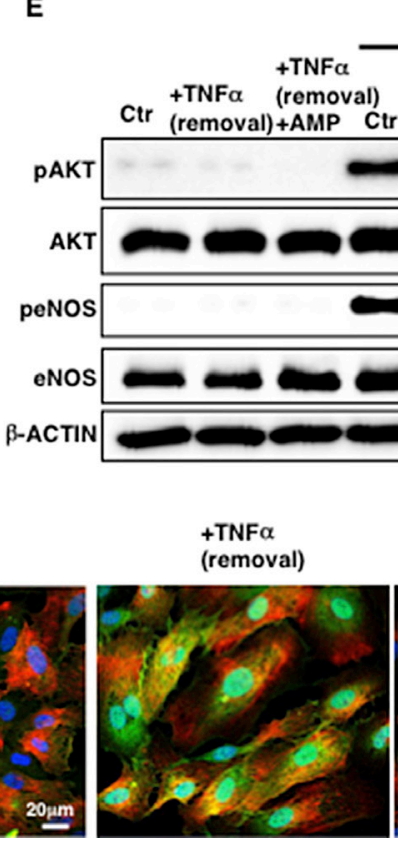

+insulin

$\overline{\mathrm{TNF} \alpha}$

(removal) + (remp
+ AMP

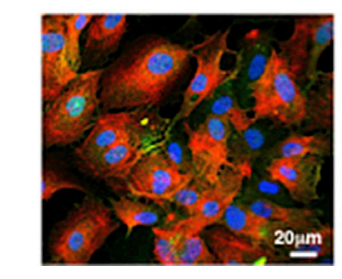

(removal)

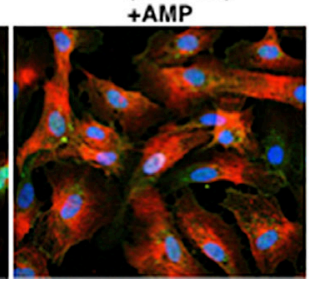

Figure 6: Induction of GM1 expression is stable in $10 \mathrm{ng} / \mathrm{ml}$ TNF $\alpha$-treated HAECs. (A) At day 0, cells were reseeded with $10 \mathrm{ng} / \mathrm{ml}$ TNF $\alpha$ in HAEC medium and incubated for 3 days. At day 3, cells were reseeded without TNF $\alpha$ and with or without AMP-dNM in HAEC medium and further incubated for 4 days. At day 7, cells were harvested and analyzed (B-G). Control cells were grown in HAEC medium. (B) Real-time PCR analysis of IRS2 and eNOS performed using cDNA derived from control, 3-day TNF $\alpha$-treated HAECs and 3-day TNF $\alpha$-treated HAECs 4 days after removal of TNF $\alpha$. Results shown were normalized against values obtained for control HAECs (value =1). (C) FACS analysis of cell surface GM1 performed in control and TNF $\alpha$-treated HAECs with or without AMP-dNM treatment for 4 days after removal of TNF $\alpha$. MFIs relative to control HAECs are shown. (D) Real-time PCR analysis of B4GALNT1 performed using cDNA derived from control and TNF $\alpha$-treated HAECs 4 days after removal of TNF $\alpha$. Results shown were normalized against values obtained for control HAECs (value $=1)$. (E) Western blot analysis of insulin signaling performed for TNF $\alpha$-treated HAECs with or without AMP-dNM treatment 4 days after removal of TNF $\alpha$. (F) Histograms show mean densitometric readings \pm SD of phosphorylated or non-phosphorylated proteins in insulin-stimulated cells normalized to loading controls ( $\beta$-ACTIN). All values were obtained from three independent experiments. (G) Immunocytochemical staining performed in TNF $\alpha$-treated HAECs with or without AMP-dNM treatment 4 days after removal of TNF $\alpha$. Representative images are shown (GM1, green; IR $\alpha$, red; DAPI, blue; GM1 and IR $\alpha$ co-localization, yellow). ${ }^{*} P<0.05 ;{ }^{* *} P<0.01$. Control (Ctr): untreated cells. 
modulates the expression of GD1a) in TNF $\alpha$-treated HAECs. Conversion of GM1 to GD1a may therefore be a rate-limiting step in HAECs. Thus, these results provide a possible explanation for the increased levels of GM1 in TNF $\alpha$-treated HAECs. Further research is required to clarify the mechanisms regulating the expression of these enzymes and to identify the key regulators of GM1 in TNF $\alpha$-treated HAECs.
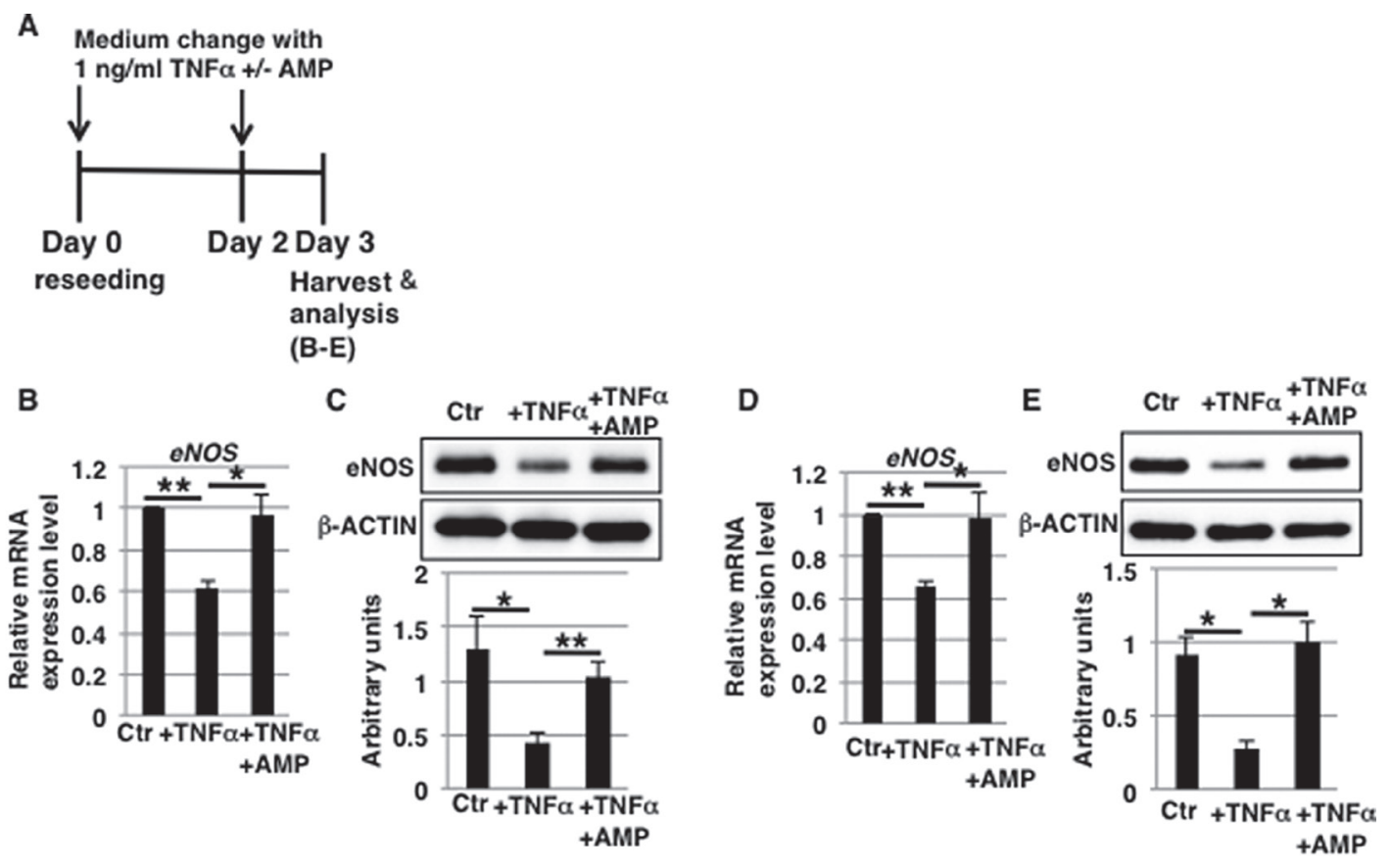

The effect of increased GM1 levels on other functions of ECs is currently unknown, but, as shown here, stable GM1 expression after removal of highly concentrated TNF $\alpha$ may contribute to other chronic dysfunctions of ECs. Further studies are required to clarify the contribution of GM1 to other functions of ECs, but we propose that GM1 is an interesting target for prevention of vascular diseases caused by chronic vascular
$\mathbf{F}$

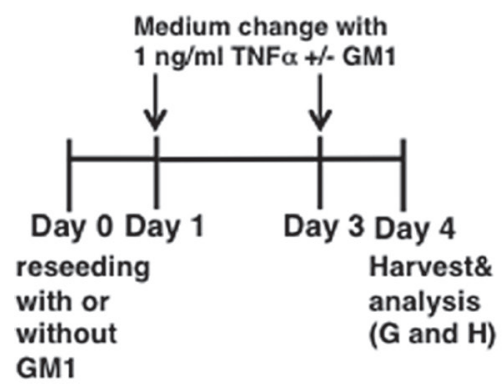

G

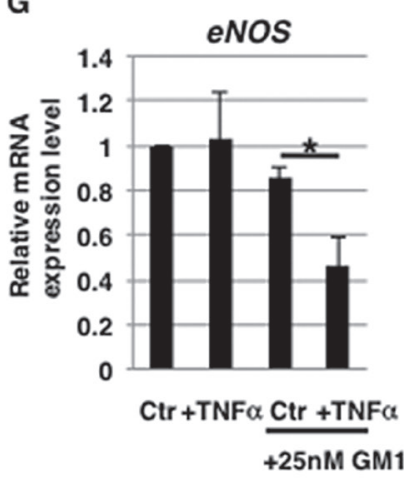

H

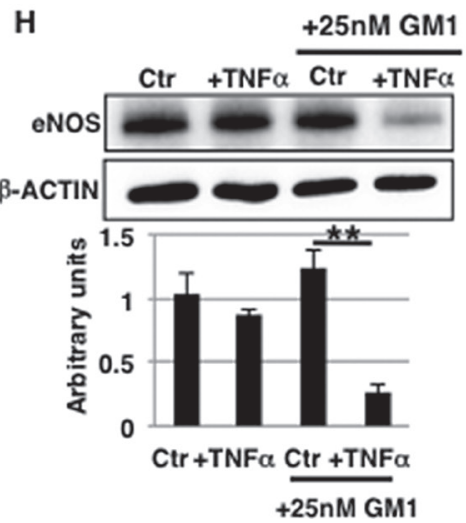

Figure 7: Aging and senescence affect eNOS levels due to increased GM1 levels in short-term $1 \mathrm{ng} / \mathrm{ml}$ TNF $\alpha$-treated HAECs. (A) At day 0, aged/senescent HAECs were reseeded with $1 \mathrm{ng} / \mathrm{ml}$ TNF $\alpha$ in HAEC medium with or without AMP-dNM and incubated for 3 days. At day 3, cells were harvested and analyzed (B-E). (F) At day 0, non-aged HAECs were reseeded with or without $25 \mathrm{nM} \mathrm{GM} 1$ in HAEC medium. At day 1, cells were treated with $1 \mathrm{ng} / \mathrm{ml} \mathrm{TNF} \alpha$ with or without $25 \mathrm{nM}$ GM1 in HAEC medium and incubated for 3 days. At day 4, cells were harvested and analyzed ( $\mathbf{G}$ and $\mathbf{H})$. Control cells were grown in HAEC medium. (B, D and G) Real-time PCR analysis of eNOS performed using cDNA derived from short-term (3 days) $1 \mathrm{ng} / \mathrm{ml} \mathrm{TNF} \alpha$-treated senescent HAECs with or without AMP-dNM treatment (B), short-term (3 days) $1 \mathrm{ng} / \mathrm{ml}$ TNF $\alpha$-treated aged HAECs with or without AMP-dNM treatment (D), and short-term (3 days) $1 \mathrm{ng} / \mathrm{ml} \mathrm{TNF} \alpha$-treated GM1-overexpressing HAECs (G). Results shown were normalized against values obtained for control HAECs (value = 1). (C, E and H) Western blot analysis of eNOS performed for short-term (3 days) $1 \mathrm{ng} / \mathrm{ml} \mathrm{TNF} \alpha$-treated senescent HAECs with or without AMP-dNM treatment (C), short-term (3 days) $1 \mathrm{ng} / \mathrm{ml} \mathrm{TNF} \alpha$-treated aged HAECs with or without AMP-dNM treatment (E), and short-term (3 days) $1 \mathrm{ng} / \mathrm{ml}$ TNF $\alpha$-treated GM1-overexpressing HAECs $(\mathrm{H})$. Histograms below Western blot panels show mean eNOS densitometric readings \pm SD normalized to those of the loading controls ( $\beta$-ACTIN). All values were obtained from three independent experiments. ${ }^{*} P<0.05 ;{ }^{* *} P<0.01$. Control (Ctr): untreated cells. 
dysfunctions. TNF $\alpha$ levels are increased after acute myocardial infarction and induce acute inflammatory responses, including vascular insulin resistance. After acute myocardial infarction, dysregulation of immune pathways, impaired suppression of post-infarction inflammation, and perturbed spatial containment of the inflammatory response may cause adverse remodeling in patients contributing to heart failure [38]. Based on our results, we speculate that chronic vascular dysfunctions caused by residual GM1 after acute myocardial infarction may be involved in the initiation and development of heart failure.

eNOS expression upon highly concentrated (above $10 \mathrm{ng} / \mathrm{ml}$ ) TNF $\alpha$ exposure is regulated through NF- $\mathrm{KB}$, eNOS 3'-UTR binding proteins, and miR-155 [39-41]. In this study, we showed that long- and short-term exposure to $1 \mathrm{ng} / \mathrm{ml} \mathrm{TNF} \alpha$ induce a reduction of eNOS levels in non-senescent HAECs and in aged/senescent HAECs, respectively (Figure $3 \mathrm{~B}-3 \mathrm{E}$ and 7 ). In these stimulated cells, increased GM1 levels contributed to eNOS downregulation presumably driving changes in the intensity of TNF $\alpha$ signaling. The TNF-receptor is controversially known to be functional on lipid rafts or non-raft regions $[42,43]$. Increased GM1 levels affect cell surface expression of raft-associated proteins and contribute to reduce membrane fluidity [19-21]. Thus, it is possible that increased GM1 levels affect the cell surface distribution of the TNF-receptor leading to changes in signal transduction. We therefore speculate that long- and short-term exposure to low concentrations of TNF $\alpha$ induce downregulation of eNOS levels in non-senescent HAECs and in aged/senescent HAECs, respectively, via activation of eNOS 3'-UTR binding proteins and miR-155 depending on the intensity of $\mathrm{TNF} \alpha / \mathrm{NF}-\kappa \mathrm{B}$ signaling. These effects are similar to the ones induced by highly concentrated (above $10 \mathrm{ng} / \mathrm{ml}$ ) $\mathrm{TNF} \alpha$ exposure. Further studies, however, are required to clarify whether increased GM1 levels affect the localization and function of the TNF-receptor and the intensity of $\mathrm{TNF} \alpha / \mathrm{NF}-\kappa \mathrm{B}$ signaling.

We have shown here that increased GM1 levels in aged and senescent ECs contribute to vascular insulin resistance caused by reduced eNOS levels even upon exposure to low concentrations of TNF $\alpha$. Notably, serum TNFa levels are known to be increased with aging and are associated with age-related diseases such as periodontal disease $[12,44]$. Increased GM1 levels as a consequence of aging and senescence may contribute to the high risk of vascular diseases caused by vascular insulin resistance via reduced eNOS levels in elderly people. Our findings therefore suggest that GM1 is an attractive target for the detection, prevention, and treatment of insulin resistance, particularly in elderly people. At the moment, beraprost sodium is available as a potential therapeutic for vascular insulin resistance that acts by upregulating eNOS levels, but therapeutic strategies still need further development [9]. Inhibition of GM1 synthesis (via AMP-dNM treatment and targeting B4GALNT1) and of the interaction between GM1 and IR or TNF $\alpha$ signaling molecules could be employed to develop new extracellular therapeutic strategies. For the clinical translation of these findings free from side effects, further studies are required to identify the key regulators of GM1 homeostasis and to clarify the molecular mechanisms underlying insulin resistance and modulation of $\mathrm{TNF} \alpha$ signaling intensity via GM1.

In conclusion, our data demonstrate that GM1 levels on the cell membrane of HAECs change depending on the time of exposure to TNF $\alpha$ and its concentration, and that these fluctuations are associated with specific extracellular/intracellular regulation of the insulin signaling cascade. Furthermore, we have demonstrated that aging and senescence affect the regulation of insulin resistance depending on GM1. Thus, based on our experiments mimicking in vivo acute or chronic inflammatory situations, we propose that GM1 is an attractive target for prevention and cure of vascular diseases including aging-related inflammatory diseases.

\section{MATERIALS AND METHODS}

\section{Cell culture}

HAECs from a 27-year-old male and an 81-year-old male were purchased from a commercial vendor (Lonza, Walkersville, MD, USA). Experiments were mainly performed using HAECs obtained from a 27-year-old male. Cells were grown in endothelial growth medium-2 (EGM-2) supplemented with growth factors, antibiotics, and 2\% fetal bovine serum (FBS) (EGM-2 SingleQuot; Lonza). Cells were passaged at $80 \%$ confluence and seeded at a density of 2,500-5,000 cells $/ \mathrm{cm}^{2}$. All experiments were performed at a confluence of $75-80 \%$. Population doubling levels (PDLs) were calculated at each passage using the following equation: $n=(\log 2 \mathrm{X}-$ $\log 2 \mathrm{Y}$ ), where $n=$ PDL, $\mathrm{X}=$ number of cells at end of passage, and $\mathrm{Y}=$ number of seeded cells at beginning of passage. The PDL at first plating of a newly purchased cell stock was defined as PDL 0 . In this study, cells (HAECs of a 27-year-old male, non-aged) with a PDL of 14-17 and cells (HAECs of an 81-year-old male, aged) with a PDL of 7-11 were used as early passage (EP, non-senescent) cells, and cells (HAECs of a 27-year-old male) with a PDL of 29-30 were used as senescent (SEN) cells. For reduction of GM1, HAECs were treated with either vehicle (ethanol) only or $10 \mu \mathrm{M}$ AMP-dNM (Cayman Chemical, Ann Arbor, MI, USA) throughout the entire culture period until they were used for experiments. For overexpression of GM1, HAECs were cultured with either vehicle (methanol) only or $25 \mathrm{nM}$ GM1 (Sigma-Aldrich, St. Louis, MO, USA) in HAEC culture medium for $24 \mathrm{~h}$. 
Table 1: List of primer sets for real-time PCR

\begin{tabular}{lll}
\hline Gene & Forward primer & Reverse primer \\
\hline ST3GAL5 & AGGAATGTCGTCCCAAGTTTG & GGAGTAAGTCCACGCTATACCT \\
B4GALNT1 & ACAGCAGACACAGTCCGGTTCT & GCGGGTGTCTTATGCGGATA \\
STSSIA1 & TACTCTCTCTTCCCACAGG & GACAAAGGAGGGAGATTGC \\
ST3GAL2 & GAAGGAGGCCAGGTTTTGC & CCCGGCCCAAGTACAGAAG \\
NEU3 & TGGACGGGCACAACTTCA & TGCCAACATCCTGCTCAAAG \\
IRS2 & AATGTGAAGTGGCAGAGGTGA & TCACAGAGCTGTCGACTCAGG \\
$F S P 1$ & GCAGAACATCCACGAGACCAT & GGAACTCGAAGAGCTCCTTGAG \\
CD 44 & TGGAGAAGGCCCTGGATGT & CCCTCTTTGCCCGAGTACTTG \\
$S N A I L$ & ACCTGCCCAATGCCTTTG & GACATAGCGGGTGCCATCAC \\
aSMA & CCCCAATCGGAAGCCTAACT & GCTGGAAGGTAAACTCTGGATTAGA \\
$S M 22$ & CACCATCGGAAATGAACGTTT & GACTCCATCCCGATGAAGGA \\
$N-C A D H E R I N$ & GGCGTGATTCTGAGCAAGCT & CACCTTCACCGGCTTGGA \\
$v W F$ & TGGGATCCGACGAATGG & GCAGATCGGACCGGATACTG \\
$e N O S$ & CGGCTTGCACCATTCAGCTA & TGCAGAAGTGAGTATCACAGCCATC \\
$p 16$ & CGGCATCACCAGGAAGAAGA & TGAGCGAGGCGGAGATCT \\
$p 21$ & CCAACGCACCGAATAGTTACG & GGGCGCTGCCCATCA \\
$p 53$ & TGGAGACTCTCAGGGTCGAAA & GCGTTTGGAGTGGTAGAAATCTG \\
$\beta-A C T I N$ & TCTCCCCAGCCAAAGAAGAA & CCACGGATCTGAAGGGTGAA \\
\hline
\end{tabular}

\section{SA- $\beta-G a l$ assay}

SA- $\beta$-Gal activity was assayed by using a senescence detection kit (BioVision Inc., Milpitas, CA, USA) as described in our previous reports [27, 45].

\section{FACS analysis}

FACS analysis was performed as described in our previous reports [22, 39]. Briefly, cells were harvested with the Accutase ${ }^{\circledR}$ cell detachment solution (Merck Millipore, Billerica, MA, USA) and dissociated single cells were incubated with primary antibodies or fluorescein isothiocyanate (FITC)-conjugated antibodies diluted in FACS buffer $(0.5 \%[\mathrm{w} / \mathrm{v}]$ bovine serum albumin [BSA] and $0.1 \%[\mathrm{w} / \mathrm{v}]$ sodium azide in phosphatebuffered saline [PBS]) for $30 \mathrm{~min}$ on ice. After washing, the cell suspension was incubated with Alexa Fluor ${ }^{\mathrm{B}}$ 488-conjugated secondary antibodies (Molecular Probes, Eugene, OR, USA) diluted in FACS buffer for $30 \mathrm{~min}$ on ice. For detection of GM1, cells were incubated with Alexa Fluor ${ }^{\circledR}$ 647-conjugated cholera toxin B subunit (Molecular Probes) diluted in FACS buffer for $30 \mathrm{~min}$ on ice. Cell sorting and analysis were performed using a FACSAria ${ }^{\mathrm{TM}}$ Cell Sorter (Becton Dickinson, Franklin Lakes, NJ, USA). We used the following FITC-conjugated antibodies and primary antibodies: FITC-conjugated anti-CD31 (Becton Dickinson), FITC-conjugated antiCD10 (Becton Dickinson), FITC-conjugated anti-
CD44 (Becton Dickinson), FITC-conjugated anti-CD90 (Miltenyi Biotec Inc., Auburn, CA, USA), anti-STRO-1 (R\&D Systems Inc., Minneapolis, MN, USA), anti-NCADHERIN (Sino Biological Inc., Beijing, China), anti-GM3 (NBT Laboratories Inc., Tokyo, Japan), antimonosyalotrihexosylceramide (GM2) (TCI, Tokyo, Japan), anti-monosyalotrihexosylceramide (GD1a) (TCI), anti-ganglioside GD3 (Merck Millipore), anti-ganglioside GD2 (TCI), anti-ganglioside GD1b (TCI), and anti-IR $\alpha$ (Abcam, Cambridge, UK). Mean fluorescence intensities (MFIs) were calculated by subtracting the intensities of the controls.

\section{Immunoblotting}

To investigate insulin signaling, the cell culture medium was replaced with EGM-2 containing $1 \%(\mathrm{v} / \mathrm{v})$ FBS for $6 \mathrm{~h}$ and cells were stimulated for 5 min with 1 $\mu \mathrm{M}$ human insulin (Wako, Osaka, Japan). Cells were lysed with lysis buffer (50 mM Tris- $\mathrm{HCl} \mathrm{pH} 7.4,150 \mathrm{mM}$ $\mathrm{NaCl}$, and $1 \%[\mathrm{v} / \mathrm{v}]$ Triton $\left.{ }^{\mathrm{TM}} \mathrm{X}-100\right)$ containing protease and phosphatase inhibitor cocktails (Roche, Indianapolis, IN, USA). Samples prepared as described above were resolved by SDS-PAGE and subsequently transferred onto PVDF membranes (Merck Millipore). After blocking, membranes were incubated with the following primary antibodies: monoclonal rabbit anti-AKT (4691; Cell Signaling Technology, Danvers, MA, USA), monoclonal rabbit anti-phosphorylated AKT (pAKT) (Ser473; 4060; 
Cell Signaling Technology), monoclonal mouse antieNOS (610297; Becton Dickinson), monoclonal rabbit anti-phosphorylated eNOS (peNOS) (Ser1177; 9570; Cell Signaling Technology), and monoclonal mouse anti$\beta$-ACTIN (A5316; Sigma-Aldrich). Membranes were subsequently incubated with the appropriate peroxidaseconjugated secondary antibodies (Cell Signaling Technology), washed and developed with ECL TM Prime reagents (GE Healthcare, Piscataway, NJ, USA). The signal was detected using a GE Healthcare ImageQuant LAS3000m.

\section{Immunostaining}

Cells were fixed with $4 \%(\mathrm{w} / \mathrm{v})$ paraformaldehyde and washed. Subsequently, cells were permeabilized with $0.2 \% \quad(\mathrm{v} / \mathrm{v})$ Triton $^{\mathrm{TM}} \mathrm{X}-100$ and blocked with PBS containing 1\%(w/v) BSA and 5\% (v/v) normal goat serum. After washing, cells were incubated with anti-FSP1 (ab27957; Abcam) at $4^{\circ} \mathrm{C}$ overnight. After washing, cells were stained with an Alexa Fluor ${ }^{\mathbb{R}}$ 546-conjugated secondary antibody (Molecular Probes) and then counterstained with DAPI. Immunofluorescence images were acquired using a fluorescence microscope (Leica Microsystems, Wetzlar, Germany). For analysis of gangliosides with or without IR $\alpha$, cells were stained without being previously permeabilized. Immunofluorescence images were acquired using a confocal laser scanning microscope (Leica Microsystems).

\section{Real-time PCR}

Total RNA was isolated from cells using the RNeasy plus mini kit (QIAGEN, Hilden, Germany) and subsequently reverse-transcribed using the ReverTra Ace $^{\circledR}$ qPCR RT Kit (Toyobo, Osaka, Japan). Realtime PCR was performed using the Power Sybr ${ }^{\circledR}$ Green kit (Applied Biosystems, Foster City, CA, USA) and the StepOnePlus ${ }^{\mathrm{TM}}$ real-time PCR system (Applied Biosystems). Primer sets for real-time PCR are listed in Table 1.

\section{Statistical analysis}

Western blot images were densitometrically analyzed with the ImageJ software (National Institute of Health). Values were expressed as means \pm SD from at least three independent experiments. Student's t tests for independent samples were used for statistical analysis.

\section{Abbreviations}

AMP-dNM, $\quad N$-(5'-adamantane-1'-yl-methoxy)pentyl-1-deoxynojirimycin; BSA, bovine serum albumin; ECs, endothelial cells; EndMT, endothelial-mesenchymal transition; eNOS, endothelial NO synthase; GM3, monosialodihexosylganglioside; HAEC, human aortic endothelial cell; IR, insulin receptor; IRS, IR substrate; MFI, mean fluorescent intensity; PBS, phosphate-buffered saline; ROS, reactive oxygen species; TNF $\alpha$, tumor necrosis factor-alpha.

\section{Author contributions}

NS designed and performed experiments, analyzed data, and wrote the paper. YI wrote the paper. MT designed experiments and wrote the paper. All authors read and approved the final version of the manuscript.

\section{ACKNOWLEDGMENTS}

We would like to express our sincere thanks to K. Saito for her secretarial work.

\section{CONFLICTS OF INTEREST}

There are no conflicts of interest.

\section{FUNDING}

This work was supported by JSPS KAKENHI Grant Numbers 25670182, 26671017 (Grant-in-Aid for Challenging Exploratory Research) and 16K08263 (Grantin-Aid for Scientific Research (C).

\section{REFERENCES}

1. Rajendran P, Rengarajan T, Thangavel J, Nishigaki Y, Sakthisekaran D, Sethi G, Nishigaki I. The Vascular Endothelium and Human Diseases. Int J Biol Sci. 2013; 9:1057-1069.

2. Draijer R, Atsma DE, van der Laarse A, van Hinsbergh VW. cGMP and nitric oxide modulate thrombin-induced endothelial permeability. Regulation via different pathways in human aortic and umbilical vein endothelial cells. Circ Res. 1995; 76:199-208.

3. Simionescu M. Implications of early structural-functional changes in the endothelium for vascular disease. Arterioscler Thromb Vasc Biol. 2007; 27:266-274.

4. Manduteanu I, Simionescu M. Inflammation in atherosclerosis: a cause or a result of vascular disorders? J Cell Mol Med. 2012; 16:1978-1990.

5. Kuo A, Lee MY, Sessa WC. Lipid Droplet Biogenesis and Function in the Endothelium. Circ Res. 2017; 120:1289-1297.

6. Ma H, Zhang HF, Yu L, Zhang QJ, Li J, Huo JH, Li X, Guo WY, Wang HC, Gao F. Vasculoprotective effect of insulin in the ischemic/reperfused canine heart: Role of Aktstimulated NO production. Cardiovasc Res. 2006; 69:57-65.

7. Rask-Madsen C, Li Q, Freund B, Feather D, Abramov R, Wu IH, Chen K, Yamamoto-Hiraoka J, Goldenbogen J, 
Sotiropoulos KB, Clermont A, Geraldes P, Dall'Osso C, et al. Loss of insulin signaling in vascular endothelial cells accelerates atherosclerosis in apolipoprotein E null mice. Cell Metab. 2010; 11:379-389.

8. Bornfeldt KE, Tabas I. Insulin resistance, hyperglycemia, and atherosclerosis. Cell Metab. 2011; 14:575-585.

9. Kubota T, Kubota N, Kumagai H, Yamaguchi S, Kozono $\mathrm{H}$, Takahashi T, Inoue M, Itoh S, Takamoto I, Sasako T, Kumagai K, Kawai T, Hashimoto S, et al. Impaired insulin signaling in endothelial cells reduces insulin-induced glucose uptake by skeletal muscle. Cell Metab. 2011; 13:294-307.

10. Artunc F, Schleicher E, Weigert C, Fritsche A, Stefan N, Häring HU. The impact of insulin resistance on the kidney and vasculature. Nat Rev Nephrol. 2016; 12:721-737.

11. Shoelson SE, Lee J, Goldfine AB. Inflammation and insulin resistance. J Clin Invest. 2006; 116:1793-1801.

12. Bruunsgaard H, Skinhøj P, Pedersen AN, Schroll M, Pedersen BK. Ageing, tumour necrosis factor-alpha (TNFalpha) and atherosclerosis. Clin Exp Immunol. 2000; 121:255-260.

13. Jung UJ, Choi MS. Obesity and its metabolic complications: the role of adipokines and the relationship between obesity, inflammation, insulin resistance, dyslipidemia and nonalcoholic fatty liver disease. Int J Mol Sci. 2014; 15:6184-6223.

14. da Costa RM, Neves KB, Mestriner FL, Louzada-Junior P, Bruder-Nascimento T, Tostes RC. TNF- $\alpha$ induces vascular insulin resistance via positive modulation of PTEN and decreased Akt/eNOS/NO signaling in high fat diet-fed mice. Cardiovasc Diabetol. 2016; 15:119.

15. Shimizu I, Yoshida Y, Katsuno T, Tateno K, Okada S, Moriya J, Yokoyama M, Nojima A, Ito T, Zechner R, Komuro I, Kobayashi Y, Minamino T. p53-induced adipose tissue inflammation is critically involved in the development of insulin resistance in heart failure. Cell Metab. 2012; 15:51-64.

16. Lingwood CA. Glycosphingolipid functions. Cold Spring Harb Perspect Biol. 2011; 3:1-26.

17. Sasaki N, Toyoda M. Glycoconjugates and Related Molecules in Human Vascular Endothelial Cells. Int J Vasc Med. 2013; 2013:1-10.

18. Varki A, Cummings RD, Esko JD, Freeze HH, Stanley P, Bertozzi CR, Hart GW, Etzler ME. Essentials of Glycobiology, 2nd ed., Cold Spring Harbor Laboratory Press, Cold Spring Harbor, NY. 2009.

19. Dong Y, Ikeda K, Hamamura K, Zhang Q, Kondo Y, Matsumoto Y, Ohmi Y, Yamauchi Y, Furukawa K, Taguchi R, Furukawa K. GM1/GD1b/GA1 synthase expression results in the reduced cancer phenotypes with modulation of composition and raft-localization of gangliosides in a melanoma cell line. Cancer Sci. 2010; 101:2039-2047.

20. Mitsuda T, Furukawa K, Fukumoto S, Miyazaki H, Urano T, Furukawa K. Overexpression of ganglioside GM1 results in the dispersion of platelet-derived growth factor receptor from glycolipid-enriched microdomains and in the suppression of cell growth signals. J Biol Chem. 2002; 277:11239-11246.

21. Nishio M, Fukumoto S, Furukawa K, Ichimura A, Miyazaki H, Kusunoki S, Urano T, Furukawa K. Overexpressed GM1 suppresses nerve growth factor (NGF) signals by modulating the intracellular localization of NGF receptors and membrane fluidity in PC12 cells. J Biol Chem. 2004; 279:33368-33378.

22. Bremer EG, Hakomori S. Gangliosides as receptor modulators. Adv Exp Med Biol. 1984; 174:381-394.

23. Hakomori S, Igarashi Y. Functional role of glycosphingolipids in cell recognition and signaling. J Biochem. 1995; 118:1091-1103.

24. Tagami S, Inokuchi J, Kabayama K, Yoshimura H, Kitamura F, Uemura S, Ogawa C, Ishii A, Saito M, Ohtsuka Y, Sakaue S, Igarashi Y. Ganglioside GM3 participates in the pathological conditions of insulin resistance. J Biol Chem. 2002; 277:3085-3092.

25. Aerts JM, Ottenhoff R, Powlson AS, Grefhorst A, van Eijk M, Dubbelhuis PF, Aten J, Kuipers F, Serlie MJ, Wennekes T, Sethi JK, O'Rahilly S, Overkleeft HS. Pharmacological inhibition of glucosylceramide synthase enhances insulin sensitivity. Diabetes. 2007; 56:1341-1349.

26. Zhao H, Przybylska M, Wu IH, Zhang J, Siegel C, Komarnitsky S, Yew NS, Cheng SH. Inhibiting glycosphingolipid synthesis improves glycemic control and insulin sensitivity in animal models of type 2 diabetes. Diabetes. 2007; 56:1210-1218.

27. Sasaki N, Itakura Y, Toyoda M. Ganglioside GM1 Contributes to the State of Insulin Resistance in Senescent Human Arterial Endothelial Cells. J Biol Chem. 2015; 290:25475-25486.

28. Sasaki A, Hata K, Suzuki S, Sawada M, Wada T, Yamaguchi K, Obinata M, Tateno H, Suzuki H, Miyagi T. Overexpression of plasma membrane-associated sialidase attenuates insulin signaling in transgenic mice. J Biol Chem. 2003; 278:27896-27902.

29. Muniyappa R, Quon MJ. Insulin action and insulin resistance in vascular endothelium. Curr Opin Clin Nutr Metab Care. 2007; 10:523-530.

30. Aerts JM, Hollak C, Boot R, Groener A. Biochemistry of glycosphingolipid storage disorders: implications for therapeutic intervention. Philos Trans R Soc Lond B Biol Sci. 2003; 358:905-914.

31. Kabayama K, Sato T, Saito K, Loberto N, Prinetti A, Sonnino S, Kinjo M, Igarashi Y, Inokuchi J. Dissociation of the insulin receptor and caveolin-1 complex by ganglioside GM3 in the state of insulin resistance. Proc Natl Acad Sci U S A. 2007; 104:13678-13683.

32. Hasegawa $Y$, Saito T, Ogihara T, Ishigaki Y, Yamada T, Imai J, Uno K, Gao J, Kaneko K, Shimosawa T, Asano T, Fujita T, Oka Y, Katagiri H. Blockade of the nuclear factor- $\kappa \mathrm{B}$ 
pathway in the endothelium prevents insulin resistance and prolongs life spans. Circulation. 2012; 125:1122-1133.

33. Pober JS, Sessa WC. Evolving functions of endothelial cells in inflammation. Nat Rev Immunol. 2007; 7:803-815.

34. Ruland J. Return to homeostasis: downregulation of NF- $\kappa B$ responses. Nat Immunol. 2011; 12:709-714.

35. Khan SY, Awad EM, Oszwald A, Mayr M, Yin X, Waltenberger B, Stuppner H, Lipovac M, Uhrin P, Breuss JM. Premature senescence of endothelial cells upon chronic exposure to TNFa can be prevented by $\mathrm{N}$-acetyl cysteine and plumericin. Sci Rep. 2017; 7:39501.

36. Muñoz-Espín D, Serrano M. Cellular senescence: from physiology to pathology. Nat Rev Mol Cell Biol. 2014; 15:482-496.

37. London NR, Zhu W, Bozza FA, Smith MC, Greif DM, Sorensen LK, Chen L, Kaminoh Y, Chan AC, Passi SF, Day CW, Barnard DL, Zimmerman GA, et al. Targeting Robo4dependent Slit signaling to survive the cytokine storm in sepsis and influenza. Sci Transl Med. 2010; 2:23 ra19.

38. Prabhu SD, Frangogiannis NG. The Biological Basis for Cardiac Repair After Myocardial Infarction: From Inflammation to Fibrosis. Circ Res. 2016; 119:91-112.

39. Goodwin BL, Pendleton LC, Levy MM, Solomonson LP, Eichler DC. Tumor necrosis factor-alpha reduces argininosuccinate synthase expression and nitric oxide production in aortic endothelial cells. Am J Physiol Heart Circ Physiol. 2007; 293:H1115-H1121.
40. Sun HX, Zeng DY, Li RT, Pang RP, Yang H, Hu YL, Zhang Q, Jiang Y, Huang LY, Tang YB, Yan GJ, Zhou JG. Essential role of microRNA-155 in regulating endotheliumdependent vasorelaxation by targeting endothelial nitric oxide synthase. Hypertension. 2012; 60:1407-1414.

41. Yi B, Ozerova M, Zhang GX, Yan G, Huang S, Sun J. Post-Transcriptional Regulation of Endothelial Nitric Oxide Synthase Expression by Polypyrimidine TractBinding Protein 1. Arterioscler Thromb Vasc Biol. 2015; 35:2153-2160.

42. Legler DF, Micheau O, Doucey MA, Tschopp J, Bron C. Recruitment of TNF receptor 1 to lipid rafts is essential for TNFalpha-mediated NF-kappaB activation. Immunity. 2003; 18:655-664.

43. Treede I, Braun A, Jeliaskova P, Giese T, Füllekrug J, Griffiths G, Stremmel W, Ehehalt R. TNF-alpha-induced up-regulation of pro-inflammatory cytokines is reduced by phosphatidylcholine in intestinal epithelial cells. BMC Gastroenterol. 2009; 9:53.

44. Nishihara R, Sugano N, Takano M, Shimada T, Tanaka $\mathrm{H}$, Oka S, Ito $\mathrm{K}$. The effect of Porphyromonas gingivalis infection on cytokine levels in type 2 diabetic mice. J Periodontal Res. 2009; 44:305-310.

45. Sasaki N, Itakura Y, Toyoda M. Sialylation regulates myofibroblast differentiation of human skin fibroblasts. Stem Cell Res Ther. 2017; 8:81. 